Provided for non-commercial research and education use. Not for reproduction, distribution or commercial use.

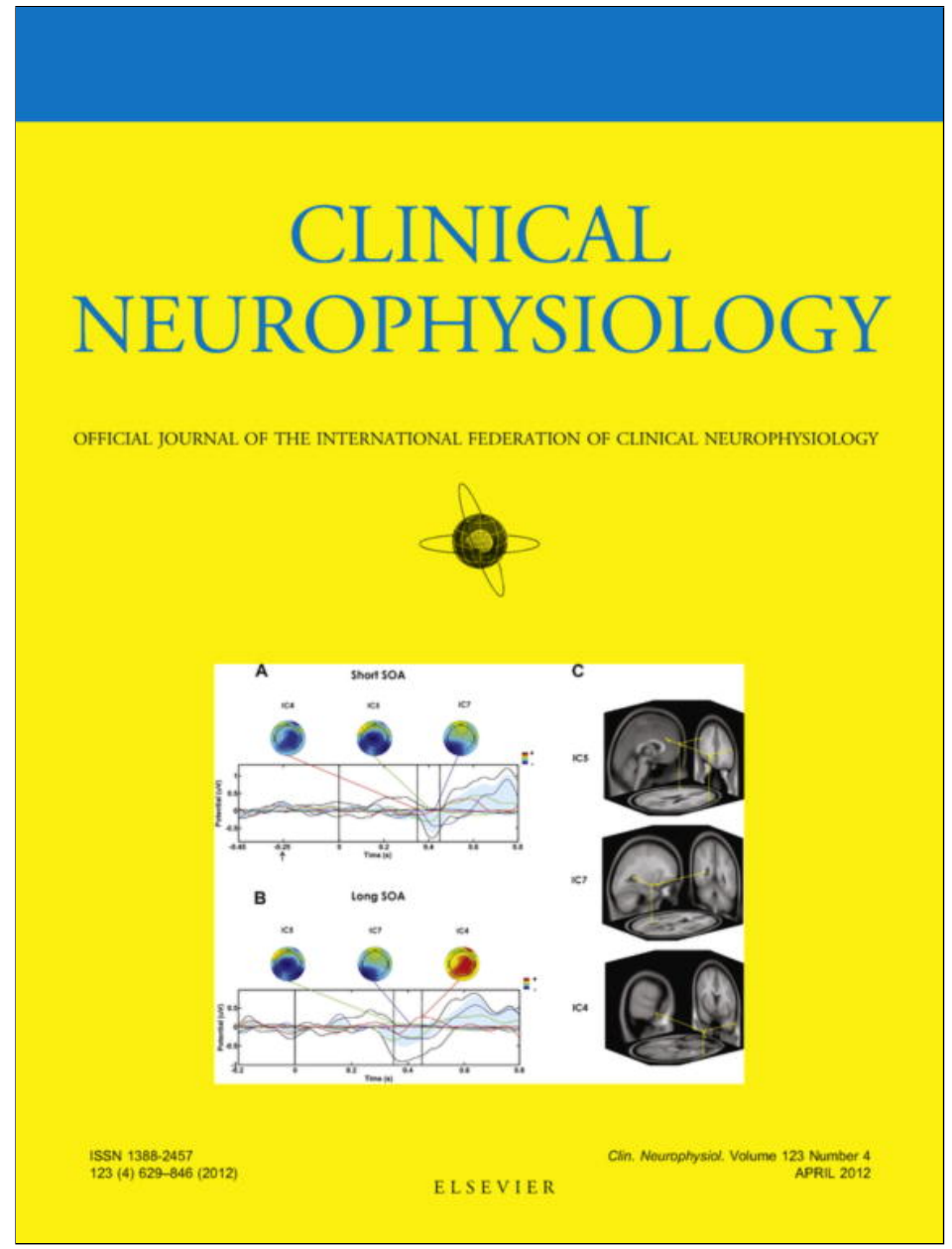

This article appeared in a journal published by Elsevier. The attached copy is furnished to the author for internal non-commercial research and education use, including for instruction at the authors institution and sharing with colleagues.

Other uses, including reproduction and distribution, or selling or licensing copies, or posting to personal, institutional or third party websites are prohibited.

In most cases authors are permitted to post their version of the article (e.g. in Word or Tex form) to their personal website or institutional repository. Authors requiring further information regarding Elsevier's archiving and manuscript policies are encouraged to visit:

http://www.elsevier.com/copyright 


\title{
Explicit semantic tasks are necessary to study semantic priming effects with high rates of repetition
}

\author{
Louis Renoult $^{\mathrm{a}, \mathrm{c}}$, Xiaoxiao Wang ${ }^{\mathrm{d}}$, Jennifer Mortimer ${ }^{\mathrm{a}}$, J. Bruno Debruille ${ }^{\mathrm{a}, \mathrm{b}, \mathrm{c}, *}$ \\ ${ }^{a}$ Douglas Mental Health University Institute, Montréal, Québec, Canada \\ ${ }^{\mathrm{b}}$ Department of Psychiatry, McGill University, Montréal, Québec, Canada

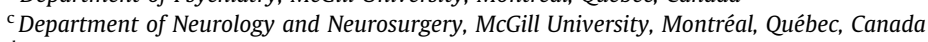 \\ ${ }^{\mathrm{d}}$ Department of Anatomy and Cell Biology, McGill University, Montréal, Québec, Canada
}

\section{A R T I C L E I N F O}

\section{Article history:}

Accepted 27 August 2011

Available online 29 September 2011

\section{Keywords:}

Event-related potentials (ERPs)

N400

Massive repetition

Semantics

Lexicality

Source analysis

\section{H I G H L I G H T S}

- Associative priming decreases N400 amplitude and reaction time (RT) to highly repeated target words. - N400 generators in the left superior temporal gyrus and inferior parietal cortex are involved in priming effects across stimulus onset asynchronies (SOAs).

- Task used, rather than SOA or the proportion of related words, is crucial for the maintenance of semantic processing with high rates of repetition.

\begin{abstract}
A B S T R A C T
Objective: The purpose of the present study was to clarify in which experimental conditions the semantic processing of repeated words is preserved.

Methods: We contrasted a short $(250 \mathrm{~ms})$ and a long $(1000 \mathrm{~ms})$ stimulus onset asynchrony (SOA) in two different experiments, using a relatively low proportion of related words (30\%). One group of participants performed a lexical decision task (LDT) and a second group performed an explicit semantic matching task with the same words (except for pseudowords) and the same task parameters. In both tasks, word stimuli consisted solely of two prime and two target words repeated throughout the experiment.

Results: The effects of semantic priming on reaction time (RT) and the amplitude of the N400 ERP were absent for both the short and the long SOA in the LDT. In contrast, in the explicit semantic task, these effects were significant. In this task, the activity of N400 generators in the left superior temporal gyrus and the inferior parietal cortex significantly differentiated primed and unprimed trials but this effect did not interact with SOA.

Conclusions: Our results indicate that task instruction is critical to preserve semantic processing with repeated presentations.

Significance: Using explicit semantic designs, it may be possible to study associative or categorical relations between individual concepts.

( 2011 International Federation of Clinical Neurophysiology. Published by Elsevier Ireland Ltd. All rights reserved.
\end{abstract}

\section{Introduction}

The most common experimental paradigm for investigating the organization of semantic memory is certainly the semantic priming paradigm (for reviews see Neely, 1991; Lucas, 2000; Hutchison, 2003). Semantic priming refers to the observation that the processing of a target word (e.g., nurse) is facilitated by the prior presentation of a semantically related prime word (e.g., doctor). This

\footnotetext{
* Corresponding author at: Human Neurocognitive Science Lab, Douglas Mental Health University Institute, 6875 Boul. LaSalle, Verdun, Québec, Canada H4H 1R3. Tel.: +1 514761 6131x3405; fax: +1 5148884099 .

E-mail address: bruno.debruille@mcgill.ca (J.B. Debruille).
}

facilitation is generally indexed by a reduction in reaction time (RT) to the target word. The semantic priming paradigm has been used to investigate associative (e.g., mouse-cheese) as well as semantic relations between words. The most investigated semantic relation has been categorical (fruit-apple). Other semantic relations include functional (broom-sweep), script or schemata (restaurant-wine), synonymy (street-road) or antonymy (blackwhite) relations. All these meaning dimensions can result in priming effects (Lucas, 2000). Interestingly, the amplitude of an event-related potential (ERP) component, the N400, has been shown to be modulated by any type of semantic or associative relations. The $\mathrm{N} 400$ is a negative deflection which develops between 250 and $500 \mathrm{~ms}$ after stimulus onset (for a review see Kutas 
et al., 2006). N400 effects of priming consists in reduced N400 amplitudes for primed or congruous words compared to unprimed or incongruous words in sentence (Kutas and Hillyard, 1980, 1984) or prime-target (Bentin et al., 1985) contexts. These effects were observed in tasks involving all mentioned semantic relations, namely category (e.g., Heinze et al., 1998), functional (Bach et al., 2009), synonymy (Liu et al., 2003), antonymy (Kutas and Iragui, 1998), schema (Chwilla and Kolk, 2005), or world knowledge (Hagoort et al., 2004) but also associative relations (Franklin et al., 2007). These findings thus indicate a systematic sensitivity of the N400 component to the processing of meaning. The neural generators of the $\mathrm{N} 400$ have been found to correspond to the extended semantic memory network described by functional neuroimaging studies (reviewed in Binder et al., 2009; Martin, 2001), including the anterior medial temporal lobe, the posterior temporal cortex, the temporoparietal junction and the ventrolateral prefrontal cortex (Smith et al., 1986; Halgren et al., 1994; Elger et al., 1997; Guillem et al., 1995, 1999).

Semantic priming is typically observed in naming or in lexical decision tasks (LDTs; Neely, 1991). In these tasks, semantic processing is implicit, since participants simply have to name target stimuli or to decide if they are words or pseudowords. For this reason, the processing of meaning in these tasks is considered to be relatively automatic, even if the presence of semantic relations between primes and targets in LDTs can influence the time it takes to decide whether the target is a word or pseudoword (Neely, 1991; Lucas, 2000; Hutchison, 2003). Larger semantic priming effects are observed in designs in which the processing of meaning is explicit, such as semantic categorization or sentence verification (Chang, 1986). In these tasks, semantic priming effects are most often referred to as effects of semantic relatedness or of semantic congruity, as they depend on an explicit assessment of semantic relations between prime and target words. Two parameters can be adjusted to favor automatic over explicit semantic processing in implicit tasks: the proportion of prime and target pairs that are related and the stimulus onset asynchrony (SOA) between prime and target. With short SOAs (e.g., less than $300 \mathrm{~ms}$ ) or with a low proportion of related words (e.g., 33\% or less), it is assumed that semantic relations are processed implicitly, whereas with longer SOAs or a higher proportion of related words controlled processes and expectancy also play a role (Neely, 1991; Lucas, 2000; Hutchison et al., 2001). The type of task, relatedness proportion and SOA are not unrelated parameters. For instance, in LDTs, the ratio of words and pseudowords is typically $50-50$, which results in a minority of target stimuli (e.g., 25-30\%) having a semantic relation to the primes. Finally, most semantic priming studies have used prime and target words that were associated, as defined by association norms (Hutchison, 2003). However, both associative and semantic relations can result in automatic priming effects (Lucas, 2000; Hutchison, 2003).

The results of almost 40 years of behavioral research have shown that effects of semantic priming are very robust. Experimental conditions that are associated with an absence of these effects are therefore of great theoretical interest (Pitzer and Dagenbach, 2001). One such condition is when target words are repeated after a limited number of intervening trials (Carroll and Kirsner, 1982; den Heyer and Benson, 1988; Besson et al., 1992; Mitchell et al., 1993; Hanze and Meyer, 1995). In this condition, these effects are reduced or suppressed, which suggests that words are no longer processed according to their semantic context. Although a number of studies have reported that this was not always the case and that, for instance, repetition and semantic priming could have additive facilitative effects on RTs (den Heyer et al., 1985; Wilding, 1986; Durgunoglu, 1988), an implicit consensus that the use of repetition should be avoided in semantic paradigms developed in Cognitive Psychology. This is unfortunate as it restricts the study of semantic categorization to the categories that subsume a sufficient number of exemplars. Even in this case, parameters such as the homogeneity of the exemplars, their typicality or the physical variance of stimuli can never be perfectly balanced (Pulvermuller and Shtyrov, 2006). Repeating the presentation of words would allow the study of categories that include only few exemplars and, more generally, the investigation of the organization of semantic representations at a finer scale than usual. However, to ensure that it could be possible, one has to verify that, at least in certain conditions, semantic processing in repeated conditions is similar to that observed in non-repeated conditions. More particularly, it should be clarified which experimental parameters are critical for the preservation or suppression of semantic effects with repetition.

In two recent studies using prime-target word pairs, we have shown preserved effects of semantic priming on RT and N400 despite the use of very high rates of repetition (Debruille and Renoult, 2009; Renoult and Debruille, 2011). In Renoult and Debruille (2011), these effects were obtained with only two prime and two target words repeated throughout the experiment. The main generators of the effect of priming in these studies were found in the superior temporal gyrus bilaterally, in the right inferior parietal cortex and in the left anterior medial temporal lobe, similar to the sources described by studies using no repetition that we have mentioned above. Five characteristics of these previous studies may explain the preservation of semantic processing with repetition. (1) In both studies, repeated target words were presented at random with equal probability so that the occurrence of one word or the other could not be predicted. This contrasts with studies in which complete sentences were repeated, making it likely that subjects could anticipate the congruous or incongruous target words before they were presented (Besson et al., 1992; Mitchell et al., 1993). (2) Both of our studies used semantic categorization tasks, that is, tasks in which the processing of meaning is explicitly required. In contrast, most studies that have reported a reduction or a suppression of semantic effects with repetition have used implicit semantic designs, typically LDTs (James, 1975; Carroll and Kirsner, 1982; den Heyer and Benson, 1988; Kounios and Holcomb, 1994; Kiefer, 2005). As previously mentioned, in these tasks access to the meaning of words is not necessary, whereas semantic effects on RT and N400 are known to be greater when subjects are explicitly encouraged to process meaning (Holcomb, 1988; Mitchell et al., 1991; West and Holcomb, 2000). (3) A relatively high proportion of words were related (50\%) in Debruille and Renoult (2009) and Renoult and Debruille (2011). (4) These studies used a long SOA between prime and target words (i.e., $2000 \mathrm{~ms}$ ). These three last characteristics (2,3 and 4) could have increased the magnitude of priming effects and therefore their resistance to repetition. (5) In both of our studies, semantic relations were categorical (e.g., animal-dog). In contrast, a vast majority of semantic priming studies have used associative relations (Hutchison, 2003). It is possible that associative relations would be differentially modulated by repetition.

The most direct way to clarify in which experimental conditions semantic priming effects are preserved for repeated words would be to use the same stimulus material while varying the experimental parameters that we have described. This was the goal of the present study. We contrasted a short $(250 \mathrm{~ms})$ and a long $(1000 \mathrm{~ms}) \mathrm{SOA}$ in two different experiments using a lower proportion of related words (30\%) than in our previous studies, and associated word pairs instead of words sharing categorical relations. One group of participants performed a LDT and a second group performed an explicit semantic matching task with the same words (except for pseudowords). In both tasks, as in Renoult and Debruille (2011), word stimuli consisted solely of two prime 
and two target words repeated throughout the experiment. Different pairs of words were used across subjects to ensure that potential priming effects would not be restricted to a particular set of stimuli.

We hypothesized that the effects of semantic priming on RT and N400 would be slightly smaller than in our previous studies because of the use of a lower proportion of related words (Holcomb, 1988; Chwilla et al., 1995; Brown et al., 2000). In contrast, we predicted that these effects would be relatively unaffected by SOA, as suggested by a number of studies using no repetition (Boddy, 1986; Hill et al., 2002; Franklin et al., 2007). Finally, rather than meaning dimension (i.e., categorical relations vs. associative relations), we hypothesized that task instruction would be critical for the preservation of semantic priming effects with repetition. Indeed, while most studies that have reported a reduction or a suppression of semantic effects have used LDTs (James, 1975; Carroll and Kirsner, 1982; den Heyer and Benson, 1988; Kounios and Holcomb, 1994; Kiefer, 2005), some of these studies used stimuli defined by semantic relations instead of association norms (James, 1975; Kounios and Holcomb, 1994; Kiefer, 2005). This makes it unlikely that the type of meaning dimension would have been crucial. In contrast, the many attributes of a concept and associated knowledge are not necessarily relevant in a LDT. In agreement with this observation are behavioral results showing that the number of semantic features have a greater influence on RTs in semantic categorization tasks than in LDTs (Pexman et al., 2008). This greater influence is also found in the activation of sensory and motor features in functional neuroimaging studies. A number of these studies have shown that activation in the ventral visual pathway was correlated with word imageability in explicit semantic designs but not in LDTs (reviewed in Binder, 2007). Other studies have shown that the activation of the motor system that is associated with the processing of action verbs (e.g., Pulvermuller, 1999) only occurred in tasks in which participants explicitly had to process the meaning of the verbs (Tomasino et al., 2008; Papeo et al., 2009). Taken together, these studies suggest that some of the features or attributes of concepts may only be activated in explicit semantic designs. Interestingly, the effects of repetition are presumed to act via a similar mechanism of "sharpening" of representations: neurons coding features that are not essential for recognizing a stimulus after repeated presentations would respond less, thereby weakening connections with other neurons in the same network and resulting in sparser neural representations (Wiggs and Martin, 1998; see also Desimone, 1996). These observations, which aimed at explaining perceptual priming, are interesting to apply to conceptual representations. As a result of repetition, some of the attributes or features of concepts may no longer be activated, thereby preventing other related concepts to benefit from this activation and resulting in sparser conceptual representations. Repetition may thus simply increase the sharpening of semantic representations in implicit semantic designs, rather than causing this phenomenon, since the studies that we have cited above tend to show that conceptual representations are sparser in such tasks compared to explicit semantic designs (Binder, 2007; Pexman et al., 2008; Tomasino et al., 2008; Papeo et al., 2009). However, it is possible that explicit attention to semantic relations may preserve semantic processing even for repeated stimuli. We thus expected that the type of task would be crucial for the maintenance of semantic processing with repeated presentations. Namely, the use of a LDT would result in a suppression of semantic priming on RT and N400 across SOAs while a preservation of these effects should be observed in the explicit semantic task. Independent component analysis (ICA) was used to investigate the neural generators of these effects and compare them to previous studies in repeated and non-repeated conditions.

\section{Methods}

\subsection{Participants}

Participants were right-handed French native speakers who reported being free of neurological and psychiatric disorders. They were recruited by newspaper advertisements among people aged between 18 and 30 years who had at least a college level of education. Twenty-four subjects participated in each task (14 females10 males, mean age: $26 \pm 3$ in the LDT and 13 females-11 males, $25 \pm 4$ in the explicit semantic matching task). Two participants were excluded from the LDT and three from the explicit semantic matching task due to excessive blinking. Two additional participants were excluded from the explicit task due to multiple behavioral responses to the same items. All participants signed an informed consent form accepted by the Douglas Institute Research and Ethics Board.

\subsection{Task and procedure}

\subsubsection{Lexical decision task}

Participants were seated comfortably in a dimly lit room in front of a computer screen placed $1 \mathrm{~m}$ from their eyes. Black words, written in Boston 15 font, were presented at the center of the screen on a white background. Primes were always words and targets were either words or pseudowords. Prime words were presented for $150 \mathrm{~ms}$ and target words for $1000 \mathrm{~ms}$. SOA between primes and targets was $250 \mathrm{~ms}$ in one block of trials and $1000 \mathrm{~ms}$ in the other block. $1-1.5 \mathrm{~s}$ after the offset of the target stimulus, a blink instruction 'clignez des yeux' appeared for $1000 \mathrm{~ms}$. The next trial began after a time interval that randomly varied between 800 and $1500 \mathrm{~ms}$.

Half of the participants had the short SOA first and then the long SOA, while the order was reversed for the other half of the participants. All participants were instructed to press one of two keys with their right index finger as rapidly and as accurately as possible according to whether the target word was a real word or a pseudoword. Response keys were counterbalanced across subjects.

There were 24 pairs of words, selected from the norms of verbal associations of Ferrand and Alario (1998) among first order associates (mean association strength: $60 \pm 17 \%$ ). The mean number of letters of target words was $5( \pm 1.4)$ and the mean base-10 logarithm of their frequency of usage was $3.72( \pm 0.5)$, according to the Brulex database (Content et al., 1990). There were 24 pseudowords. They were orthographically legal and pronounceable and were derived by replacing one letter near the center of a real word (never the first or the last letter). None of these real words shared any known semantic relations with the primes. Their mean base-10 logarithm frequency of usage was $3.12( \pm 0.5)$. Pseudowords were designed to have the same average number of letters as the words $5( \pm 1.4)$.

Twelve lists of words were created, each containing two primes, two target words and two target pseudowords. In each list, the four target stimuli had the same number of letters and the two target words, very similar frequency of usage (i.e., difference in frequency smaller than 10\%). Each list of words was used twice: once in the block of trials with a short SOA and once in the block of trials with a long SOA, but in different participants. Each participant thus saw different list of words in each SOA. There were a total of 200 trials by SOA. Each word was presented 50 times: 30 times in the primed and 20 times in the unprimed condition. Each pseudoword was presented 50 times. In each SOA, the target words were related to the primes in $30 \%$ of the trials.

\subsubsection{Explicit semantic matching task}

The explicit semantic matching task differed from the lexical decision in two respects. First, pseudowords were removed. 
Second, the task instruction was changed: participants were instructed to press one of two keys with their right index finger as rapidly and as accurately as possible according to whether the meaning of the target word was related or not related to that of the prime word.

\subsection{Data acquisition}

The accuracy and RTs of participants were recorded for each trial. The EEG was recorded continuously with tin electrodes mounted in an elastic cap (Electrocap International) from 30 active points, all referenced to the right ear lobe. Twenty-eight of these points were placed according to the extended International 10-20 System (Electrode nomenclature committee, 1991). These electrode sites could be grouped in a sagittal subset, which comprised $\mathrm{Fz}, \mathrm{FCz}, \mathrm{Cz}$, and Pz; a para-sagittal subset, including FP1/2, F3/4, $\mathrm{FC} 3 / 4, \mathrm{C} 3 / 4, \mathrm{CP} 3 / 4, \mathrm{P} 3 / 4$, and $\mathrm{O} 1 / 2$; and a lateral subset, including F7/8, FT7/8, T3/4, TP7/8, and T5/6. The remaining two active electrodes were placed below each eye in order to allow the monitoring of vertical eye movements by comparing their EEG signals to those derived from FP1 and FP2. The monitoring of horizontal eye movements was done by comparing F8 to F7 signals. The impedance was kept below $5 \mathrm{k} \Omega$. The EEG was amplified 20,000 times by Contact Precision amplifiers, except for channels FP1, FP2, F8 and F7 which were initially amplified 10,000 times to prevent saturations (and then readjusted to fit the scale of the other electrodes). High and low-pass filter half-amplitude cut-offs were set at .01 and $100 \mathrm{~Hz}$, respectively, with an additional $60 \mathrm{~Hz}$ electronic notch filter. Signals were then digitized on-line at a sampling rate of $256 \mathrm{~Hz}$ and stored along with stimulus and response codes for subsequent averaging using the Instep (version 4.3) software package.

EEG epochs contaminated by eye movements, excessive myogram, amplifier saturations or analog to digital clippings were removed offline by setting automatic rejection criteria. Trials for which analog to digital clipping exceeded a $100 \mathrm{~ms}$ duration, and electrodes for which amplitude exceeded $\pm 100 \mu \mathrm{V}$ were excluded from averaging. This resulted in the following percentage of rejected trials: lexical decision task in the short SOA: $2.1 \pm 0.4 \%$ of word trials, $2.3 \pm 0.3 \%$ of pseudowords trials; $1.4 \pm 1.8 \%$ of primed and $1.5 \pm 0.7 \%$ of unprimed trials. Lexical decision task in the Long SOA: $1.9 \%$ of Word trials $\pm 0.2,2.2 \%$ of pseudoword trials $\pm 0.9 ; 1.3 \%$ of primed \pm 0.3 and $1.5 \%$ unprimed trials \pm 0.4 . Explicit semantic matching task in the short SOA: $2.1 \pm 0.8 \%$ for primed and $2.9 \pm 1.2 \%$ for unprimed trials. Explicit semantic matching task in the long SOA: $2.7 \pm 1.8 \%$ for primed and $3.2 \pm 2.1 \%$ for unprimed trials. These low numbers of rejected trials were due to the use of a dedicated blink epoch in each trial (see Section 2.2). We then further ensured that the signals recorded by frontal electrodes were not contaminated by ocular activity. For vertical eye movements, this was done by comparing the activity recorded by FP1/2 channels to that recorded by the electrodes placed below each eye, subject by subject and condition by condition, looking for polarity inversions. Similarly, for horizontal eye movements, we compared F8 signal to F7 signal and looked for polarity inversions that could signal ocular activity. No subject had to be re-averaged after this inspection.

\subsection{Data processing and measures}

Mean RTs for each condition were computed using only the correct responses and excluding the trials in which participants took more than 2000 ms to respond. ERPs were computed by averaging the EEG epochs of these trials in each experimental condition, using a -200 to $0 \mathrm{~ms}$ baseline before target onset for the long SOAs and -450 to -250 for the short SOA. This last baseline corresponded to a $200 \mathrm{~ms}$ time period before the onset of the prime and allowed to prevent a contamination from the ERPs evoked by the prime in the short SOA (e.g., Hill et al., 2002, 2005). ${ }^{1}$ Epochs of $1 \mathrm{~s}$ for the long SOA ( -200 to $800 \mathrm{~ms}$ after target word onset; 256 time points) and of $1.25 \mathrm{~s}$ for the short SOA ( -450 to $800 \mathrm{~ms}$ after target word onset; 321 time points) were thus obtained.

To measure the amplitude of the $\mathrm{N} 400$, we computed the mean voltage respective to the baseline in a time window that was chosen with a mid-peak latency technique, also referred to as the fractional latency approach in the guidelines of Picton et al. (2000). This was done because the classic $300-500$ ms time window cannot be chosen to measure the N400-like potential observed with high rates of repetition as this deflection was shown to peak earlier than the classic N400 and to be temporally less extended (Debruille and Renoult, 2009; Renoult and Debruille, 2011; Renoult et al. 2010). The latency of the negative peak that appeared between 200 and $500 \mathrm{~ms}$ at $\mathrm{Cz}$ electrode on the grand average of unprimed trials was first measured. In both experiments, this negative peak culminated around $320 \mathrm{~ms}$ after target word onset for the short SOA and around $290 \mathrm{~ms}$ post-target in the long SOA. We then measured the peak latencies of the preceding P200s. These latencies were added to the latency of those of the N400 and this sum was divided by 2 . The result was used as the onsets of the N400 time windows. Similarly, the peak latencies of the N400 were added to that of the succeeding late positive complex (LPC) and the result was divided by 2 to obtain the offsets of the N400 time windows. As the limits of the time windows obtained only differed by a few ms across experiments, a $280-460 \mathrm{~ms}$ for the short and a $240-420 \mathrm{~ms}$ for the long SOA were used in both the LDT and the explicit semantic matching task to measure the N400 deflection.

\subsection{Statistical analyses}

For analyzing behavioral data, we ran two series of repeatedmeasures ANOVAs. One was conducted for the numbers of errors (accuracy) and the other for mean RTs (excluding incorrect responses). In both series, one ANOVA was conducted for semantic priming (primed vs. unprimed trials), and had this factor and SOA (short vs. long) as within-subjects factors. For the LDT, another ANOVA was run for lexicality (words vs. pseudowords), and had this factor and SOA as within-subjects factors.

For ERP data, three repeated-measures ANOVAs were performed with the same within-subject factors as the RT analysis plus the electrode factor: 1 for the sagittal subset, 1 for the parasagittal subset and 1 for the lateral subset of electrodes. For the para-sagittal and the lateral subsets, another within-subject factor, hemiscalp (right vs. left), was included. The Greenhouse and Geisser (1959) procedure was used to compensate for possible violations of the sphericity assumption associated with the electrode factor which had more than 2 levels. In this case, the original degrees of freedom are reported together with the epsilon $(E)$ and the corrected probability level.

In an attempt to compare experiments, pseudoword trials of the LDT were omitted and mixed-models ANOVAs were performed for behavioral data and ERPs with the factor task as between-subjects factor. These ANOVAs were run with semantic priming (primed vs. unprimed trials) and SOA (short vs. long) as within-subjects factors.

\subsection{Independent component analysis (ICA)}

To identify the neural generators of the N400 effects of semantic priming and lexicality, ERPs of individual subjects from all 30

\footnotetext{
${ }^{1}$ Another statistical analysis performed with a -200 to 0 baseline before prime onset for both SOAs resulted in very similar results
} 
channels were submitted to ICA. ICA decomposes the unaveraged EEG (Jung et al., 2001) or the event-related potentials (Makeig et al., 1999; Dien et al., 2007) into a sum of sparsely activated independent components with fixed scalp maps and maximally independent time courses (Makeig et al., 1997). For non-artifactual components, these component maps have been shown to nearly fit the projection of a single equivalent current dipole, allowing hypotheses as to the localization of this dipole (Onton et al., 2006). The ICAs were conducted with EEGLAB 6.01b (Delorme and Makeig, 2004), a freely available open source toolbox (http:// www.sccn.ucsd.edu/eeglab), running under Matlab 7.7 (The Mathworks).

\subsubsection{Lexical decision task}

Since only the effect of lexicality was found to be significant in the LDT, ICA was only applied to this effect. Individual subject ERPs of $1 \mathrm{~s}$ for the long SOA ( -200 to $800 \mathrm{~ms}$ after target word onset) and of $1.25 \mathrm{~s}$ for the short SOA ( -450 to $800 \mathrm{~ms}$ after target word onset) from our 30 active electrodes were concatenated separately for words and pseudowords, yielding two matrices of $30 \times 5632$ points ( 22 subjects $\times 256$ time points) for the long SOA and two matrices of $30 \times 7062$ points ( 22 subjects $\times 321$ time points) for the short SOA, which were submitted to the same ICA. We applied infomax ICA (Bell and Sejnowski, 1995) with the EEGLAB function runica (Delorme and Makeig, 2004). The PCA option of runica was used as a preprocessing step to reduce data dimensionality and prevent individual differences to influence the decomposition (Dien et al., 2007). Ten factors were retained as a prior PCA revealed that this was the average numbers of factors needed to account for $95 \%$ of variance of the effect of lexicality across SOAs in the complete averaging period.

We then used the envtopo() function of EEGLAB (Delorme and Makeig, 2004; Onton et al., 2006) to identify the independent components (ICs) that together accounted for at least $80 \%$ of the variance of the effect of lexicality (i.e., pseudowords-words) in the N400 time window (350-450 ms after word onset). The activity of each of these ICs was then submitted to a repeated-measures ANOVA with lexicality (words vs. pseudowords) and SOA (short vs. long) as within-subject factors. Finally, source localization was computed for these ICs with DIPFIT2, an EEGLAB plug-in that performs component localization by fitting an equivalent current dipole model using a non-linear optimization technique (Scherg, 1990; Lutkenhoner, 1998). For source localization, an average reference was first calculated and the 2 eye channels were excluded. ICs for which scalp maps indicated a left-right symmetric activity were fit using 2 dipoles constrained to be located symmetrically across the (corpus callosum) midline. The head model used for the analyses was the spherical model (BESA) that is co-registered with the average Montreal Neurological Institute (MNI) brain. Spherical dipole coordinates were converted to Talairach coordinates by DIPFIT using a non-linear transform of MNI to Talairach implemented in the Matlab function "mni2tal.m" (http://imaging.mrc-cbu.cam.ac.uk/imaging/MniTalairach). The brain structures where the dipoles were localized were identified using the Talairach atlas coordinates (Talairach and Tournoux, 1988). The location solution was restricted to the gray matter, within a search range of $3 \mathrm{~mm}$.

\subsubsection{Explicit semantic matching task}

In the explicit matching task, ICA was applied to the effect of semantic priming. Individual subject ERPs of $1 \mathrm{~s}$ for the long SOA ( -200 to $800 \mathrm{~ms}$ after target word onset) and of $1.25 \mathrm{~s}$ for the short SOA ( -450 to $800 \mathrm{~ms}$ after target word onset) from our 30 active electrodes were concatenated separately for primed and unprimed trials, yielding two matrices of $30 \times 4864$ points ( 19 subjects $\times 256$ time points) for the long SOA and two matrices of $30 \times 6099$ points
(19 subjects $\times 321$ time points) for the short SOA, which were submitted to the same ICA. We applied infomax ICA (Bell and Sejnowski, 1995) with the EEGLAB function runica (Delorme and Makeig, 2004). The PCA option of runica was used as a preprocessing step as in the LDT and 10 factors were retained. We then used the envtopo() function of EEGLAB (Delorme and Makeig, 2004; Onton et al., 2006) to identify the independent components (ICs) that together accounted for at least $80 \%$ of the variance of the effect of semantic priming (i.e., unprimed-primed) in the N400 time window (280-460 ms after target word onset for the short SOA and 240-420 ms for the long SOA, as for mean voltage analyses of this effect). The activity of each of these ICs was then submitted to a repeated-measures ANOVA with priming (primed vs. unprimed) and SOA (short vs. long) as within-subject factors. Finally, source localization was computed for these ICs, as in the LDT.

\section{Results}

\subsection{Effects of task}

\subsubsection{Behavioral data}

The mixed-model ANOVA on errors showed no significant interaction involving the factor task (all $p>.09$ ). The number of errors thus did not differ significantly between the tasks (1\% of trials in the lexical decision task and 3\% of trials in the explicit semantic task). The ANOVA on mean RTs showed that the effect of semantic priming interacted with that of task $\left(F_{1,39}=7.73, p=.009\right)$ but that there was no interaction involving SOA. In the lexical decision task, unprimed trials ( $676 \mathrm{~ms}$ ) differed by only $5 \mathrm{~ms}$ from primed trials (671 ms; $p>.1$ ), whereas in the explicit semantic matching task they differed by $44 \mathrm{~ms}$ ( 791 and $747 \mathrm{~ms}$, respectively; $F_{1,18}=9.35$, $p=.008$ ). Further analyses of the effect of semantic priming for each task are described below.

\subsubsection{Electrophysiological data: mean voltage analyses}

The mixed-model ANOVA on the mean voltage amplitudes of the N400 showed that the effect of priming interacted with that of task for each subset of electrodes $\left(F_{1,39}=14.69, p<.001\right.$ for the sagittal, $F_{1,39}=13.78, \quad p=.001$ for the para-sagittal and $F_{1,39}=9.38, p=.004$ for the lateral subset of electrodes). At the sagittal subset, the mean effect of priming (unprimed-primed trials) was of $-1.7 \mu \mathrm{V}$ in the explicit semantic matching task and $+0.2 \mu \mathrm{V}$ in the lexical decision task. The effect was never significant in the lexical decision task (all $p>.1$ ) but it was significant for all subsets of electrodes in the lexical decision task $\left(F_{1,18}=14.51\right.$, $p=.001$ for the sagittal, $F_{1,18}=12.18, p=.004$ for the para-sagittal and $F_{1,18}=10.73, p=.004$ for the lateral subset of electrodes). There were also interactions between task, priming and SOA for the parasagittal $\left(F_{1,39}=5.66, p=.024\right)$ and the lateral $\left(F_{1,39}=5.43, p=.025\right)$ subsets, indicating that the effect of priming was greater in the long SOA in the explicit semantic task (see below).

\subsection{Lexical decision task}

\subsubsection{Behavioral data}

The analyses of errors showed that subjects were accurate in their responses, with a mean error rate of $1.7 \%$. The percentage of errors did not vary with SOA. It was slightly greater for primed (1.3\%) than unprimed trials $(1 \%)$ but this difference only approached significance $\left(F_{1,21}=3.22, p=.088\right)$. However, it was significantly greater for pseudowords $(2.2 \%)$ than for words $(1.1 \%)$ $\left(F_{1,21}=13.02, p=.002\right)$.

The analyses of mean RTs showed no main effects of semantic priming (mean RTs of $671 \pm 87 \mathrm{~ms}$ for primed and $676 \pm 89 \mathrm{~ms}$ for unprimed target words) or any interaction with SOA (all 
$p>.1$ ) (see Fig. 1A). There was a main effect of lexicality $\left(F_{1,21}=19.27, p<.001\right)$ showing that RTs were longer for pseudowords ( $709 \pm 79 \mathrm{~ms})$ than for words $(674 \pm 87 \mathrm{~ms})$. However, there was no main effect of SOA, nor any interaction between SOA and lexicality (see Fig. 1B).

\subsubsection{Electrophysiological data: mean voltage analyses}

Fig. 2 represents the grand averages ERPs elicited by the target words in the short (top) and the long SOA (bottom), separating primed and unprimed trials. At $\mathrm{Cz}$ electrode, the $\mathrm{N} 400$ deflections peaked around $320 \mathrm{~ms}$ after target onset in the short and around $290 \mathrm{~ms}$ in the long SOA. In both cases, primed (in red) and unprimed (in blue) trials were indistinguishable. Statistical analyses of the mean voltage amplitudes of the $\mathrm{N} 400$ confirmed these observations and showed no significant effect of semantic priming, nor any interaction implicating this factor for any subset of electrodes (all $p>.1$ ).

Fig. 3 represents the grand averages for the effect of lexicality. Pseudowords (in blue) were slightly more negative than words (in red) both in the short (top) and the long (bottom) SOA. Statistical analyses of the mean voltage amplitudes of the N400 showed a main of lexicality only for the lateral subset of electrodes $\left(F_{1,21}=7.19, p=.015\right)$. For this subset, pseudowords were associated with greater N400 amplitudes than words. This effect did not interact with any other factor.

The relative lack of significance of the effect of lexicality could be due to its late timing. The difference between words and pseudowords was maximal in the downhill slope of the N400 deflection and peaked around $400 \mathrm{~ms}$ after target onset in the long and the short SOAs, as indicated by the difference wave of Fig. 3 (in black). The time window chosen thus started a bit early to properly capture this effect (280-460 ms for the short and $240-420 \mathrm{~ms}$ post-target for the long SOA). Another analysis of this effect was

\section{A. Semantic Priming}

RT(s) Short SOA

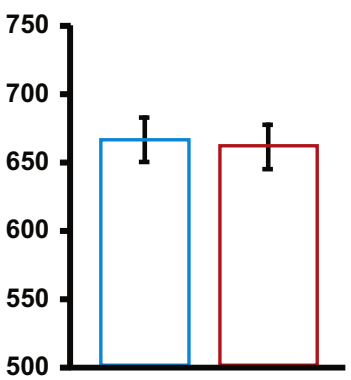

\section{B. Lexicality}

RT(s) Short SOA

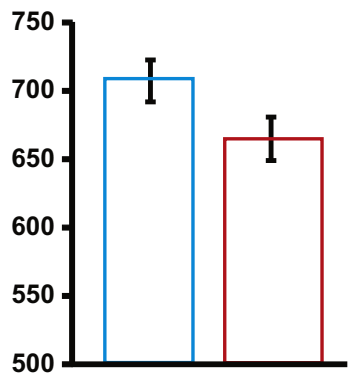

RT(s) Long SOA

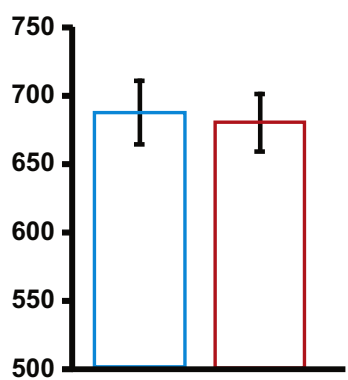

RT(s) Long SOA

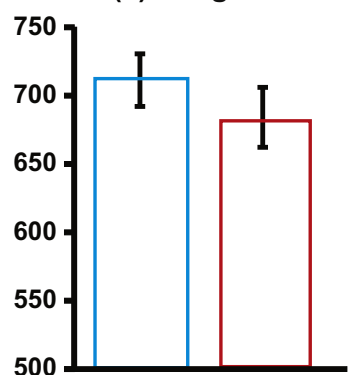

Fig. 1. Mean RTs in the lexical decision task. Standard errors bars are shown for each condition. (A) Mean RTs to primed (in red) and unprimed (in blue) target words in the short and the long SOA. (B) Mean RTs to target words (in red) and pseudowords (in blue) in the short and the long SOA. (For interpretation of the references to color in this figure legend, the reader is referred to the web version of this article.) thus done in a 350-450 time window for both SOAs. This analysis revealed a main effect of lexicality for all subsets of electrodes $\left(F_{1,21}=10.06, p=.005\right.$ for the sagittal, $F_{1,21}=11.05, p=.004$ for the para-sagittal and $F_{1,21}=22.31, p<.001$ for the lateral subset of electrodes). No significant interactions with SOA or the electrode factor were found. However, there was a triple interaction between lexicality, SOA and hemiscalp at the para-sagittal subset $\left(F_{1,21}=5.44, p=.031\right)$, illustrating that the effect of lexicality was greater over the left hemiscalp (LH) than over the right hemiscalp $(\mathrm{RH})$, especially in the long SOA (see the voltage maps of Fig. 4). Follow-up analyses showed that the effect of lexicality was significant for both hemiscalps for the short (LH: $F_{1,21}=6.33, p=.020$; RH: $\left.F_{1,21}=5.41, p=.030\right)$ and the long SOA (LH: $F_{1,21}=10.32$, $\left.p=.005 ; \mathrm{RH}: F_{1,21}=4.61, p=.045\right)$.

\subsubsection{Electrophysiological data: independent component analysis (ICA)}

In the N400-time window, three independent components (IC5, IC7 and IC4) accounted for more than $80 \%$ of the effect of lexicality in the short and the long SOAs (see Fig. 5A and B). Note that because ICs are not spatially orthogonal, the variance accounted for by all components together does not equal the sum of the variance accounted by each component alone (Groppe et al., 2008).

IC5 had a central midline scalp distribution and was the greater contributor to the effect of lexicality in the short (Percent Variance Accounted For: $\mathrm{PVAF}=51 \%$ ) and in the long $(\mathrm{PVAF}=45 \%) \mathrm{SOAs}$. This IC made its peak contribution to the effect of lexicality later in the short (i.e., $398 \mathrm{~ms}$ after target word onset) than in the long SOA (351 ms after target onset). Statistical analyses of its mean activity showed a main effect of lexicality $\left(F_{1,21}=8.91, p=.008\right)$, but no interaction with SOA. Dipole source modeling for this IC revealed that it was best modeled with a bilateral source in the dorsolateral prefrontal cortex (see Fig. 5C), in the vicinity of Brodmann area (BA) 46. ( $x:-47, y: 33, z: 18)$. The residual variance of the dipole model (RVDM) was $9 \%$.

IC7 had a left occipito-temporal scalp distribution and PVAFs of $40 \%$ and $25 \%$ in the short and long SOAs, respectively. As IC5, this IC made its greater contribution to the effect of lexicality slightly later in the short (429 ms after target word onset) than in the long SOA (413 ms after target onset). Its activity significantly differentiated words and pseudowords $\left(F_{1,21}=8.98, p=.007\right)$, but no interaction with SOA was found. This IC was best modeled as a generator in the medial part of the left temporal lobe, in the vicinity of the hippocampus ( $x$ : $-30, y:-45, z: 9)$, with a RVDM of $5 \%$.

Finally, IC4 had a right centro-parietal scalp distribution and PVAFs of $7 \%$ in the short and $-2 \%$ in the long SOA. In the long SOA, this negative PVAF was due to a positive contribution of this component in the latest part of the window (maximum at $448 \mathrm{~ms}$ after target word onset) while the mean voltage values were negative. In contrast, this IC made a negative contribution to the effect of lexicality during the first part of the window (PVAF of 26\%) at approximately the same time as in the short SOA (maximum contribution $366 \mathrm{~ms}$ after target word onset in the long SOA and $363 \mathrm{~ms}$ after target onset in the short SOA). Statistical analyses of its mean activity showed that it did not significantly differentiated words from pseudowords $(p>.1)$. This absence of significativity may have been due to the change of polarity in its contribution during the time window of analysis. This IC was best fit as a generator in the right middle temporal gyrus (BA21; $x$ : 61, $y: 5$, $z$ : -21$)$, with a RVDM of $9 \%$.

\subsection{Explicit semantic matching task}

\subsubsection{Behavioral data}

The analyses of errors showed that participants were reasonably accurate in their responses, with a mean error rate of $3 \%$. 


\section{Short SOA}

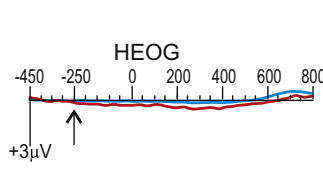

Primed Target Words

Unprimed Target Words
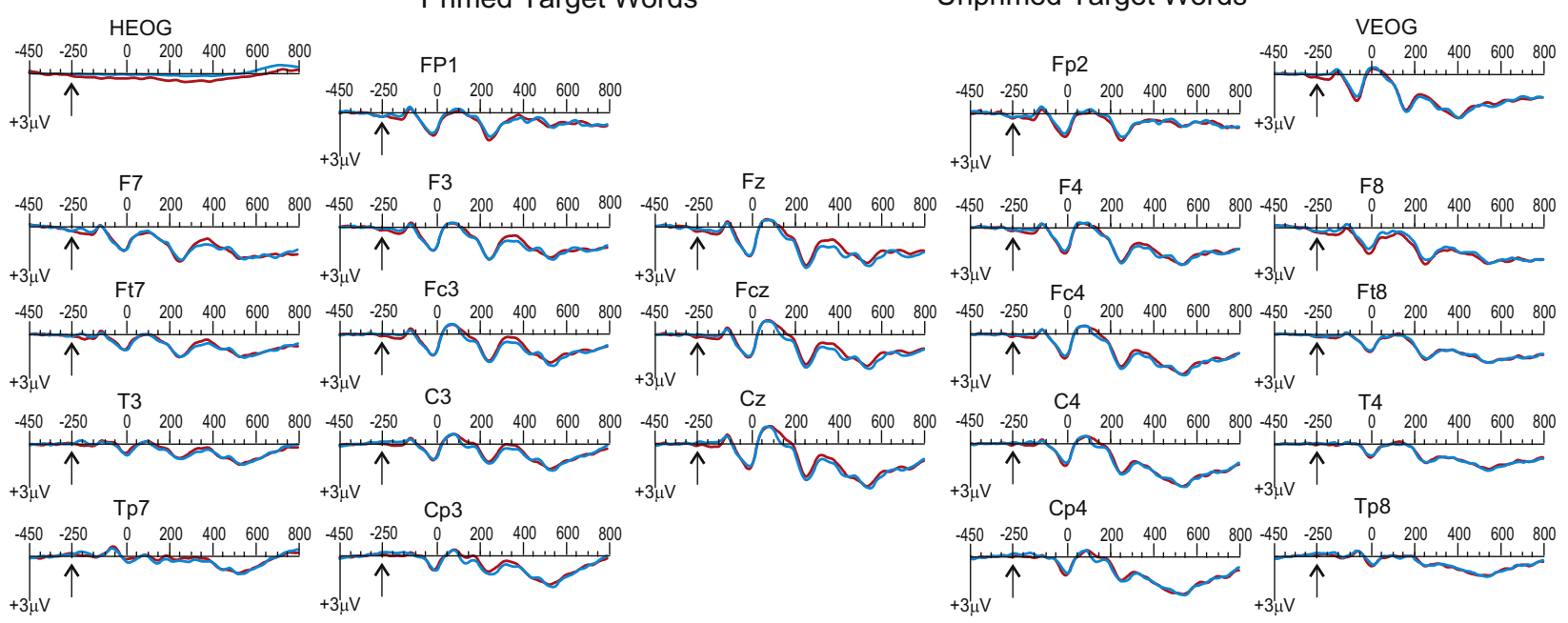

T5 P3 Pz
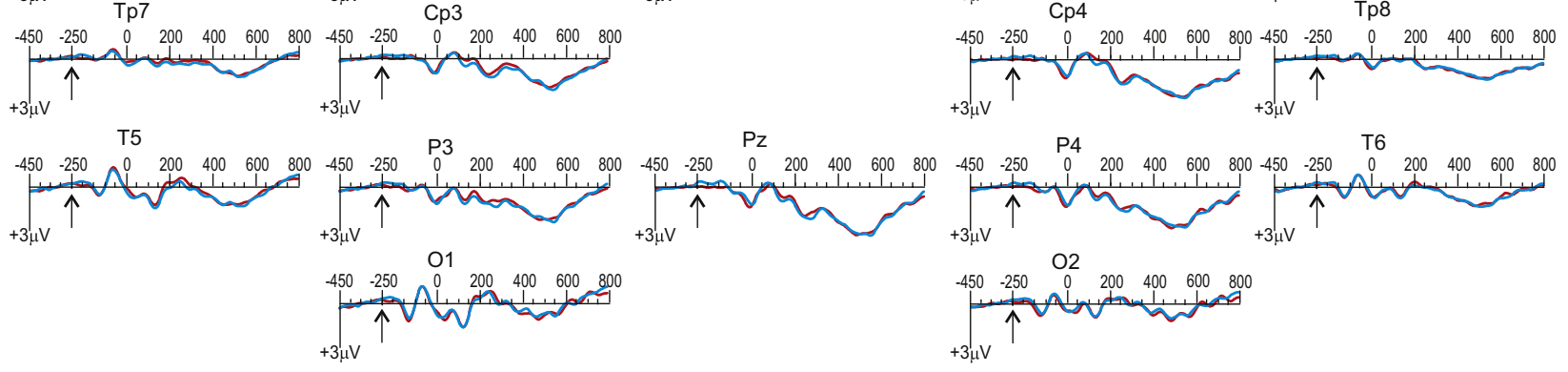

\section{Long SOA}

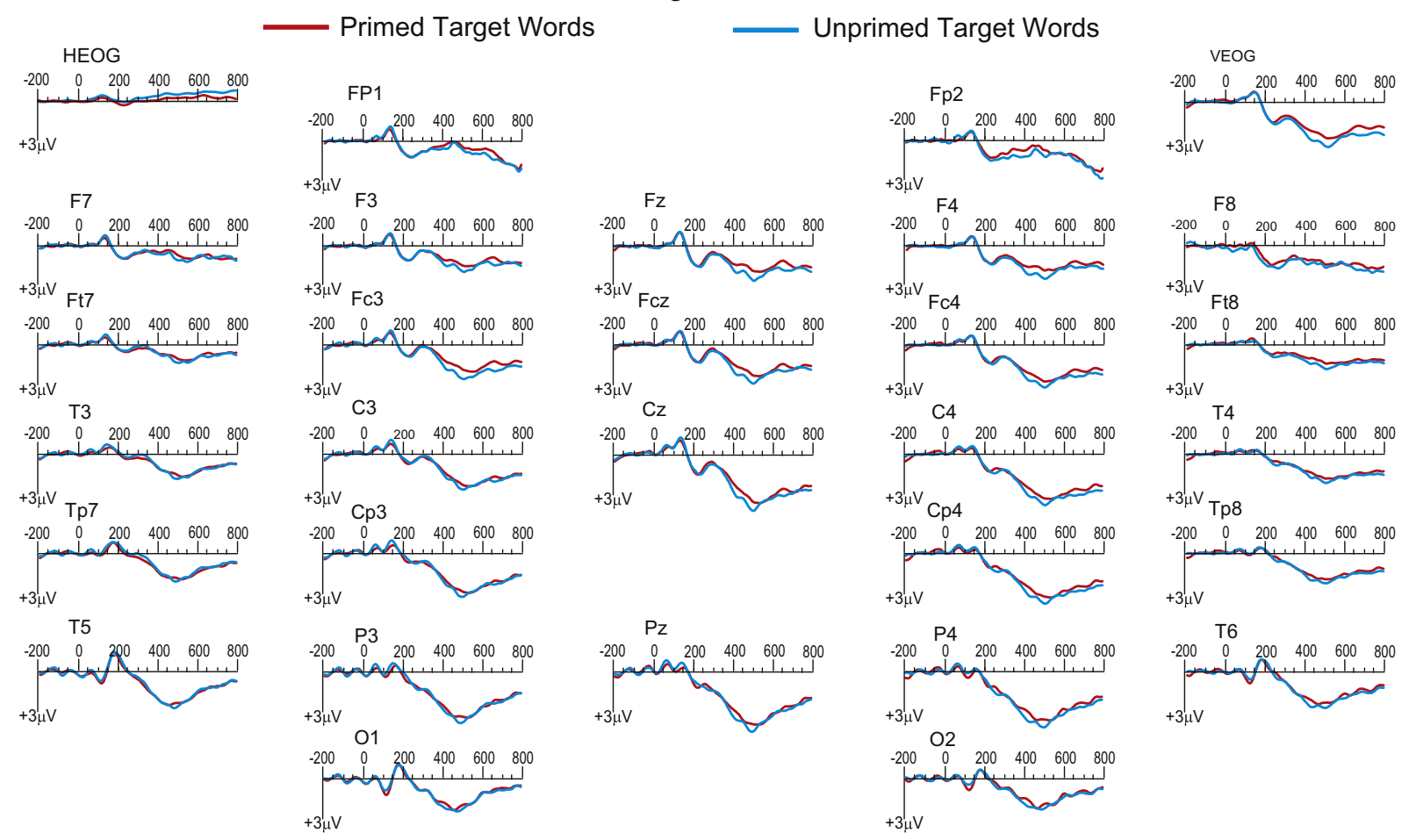

Fig. 2. Grand average ERPs $(N=22)$ to primed and unprimed target words in the short (top) and the long SOA (bottom) in the lexical decision task. Negativity is up. The short SOA was $250 \mathrm{~ms}$ and the long $1000 \mathrm{~ms}$. In the short SOA, ERPs were computed with a -450 to $-250 \mathrm{~ms}$ baseline before target onset. This baseline corresponded to a $200 \mathrm{~ms}$ period before prime onset (to prevent contamination from the ERPS evoked by the prime). The arrow in the timeline indicates prime onset. In the long SOA, ERPs were computed with a -200 to 0 baseline before target onset.

The number of errors did not vary with SOA or semantic priming (all $p>.5$ ).

The analyses of mean RTs revealed a main effect of semantic priming $\left(F_{1,18}=9.35, p=.008\right)$, showing that unprimed trials were associated with longer RTs $(791 \pm 237 \mathrm{~ms})$ than primed trials ( $747 \pm 187 \mathrm{~ms}$ ). There was also a trend for an interaction between semantic priming and $\operatorname{SOA}\left(F_{1,18}=3.29, p=.088\right)$. This was due to a greater difference between primed and unprimed trials for the long 

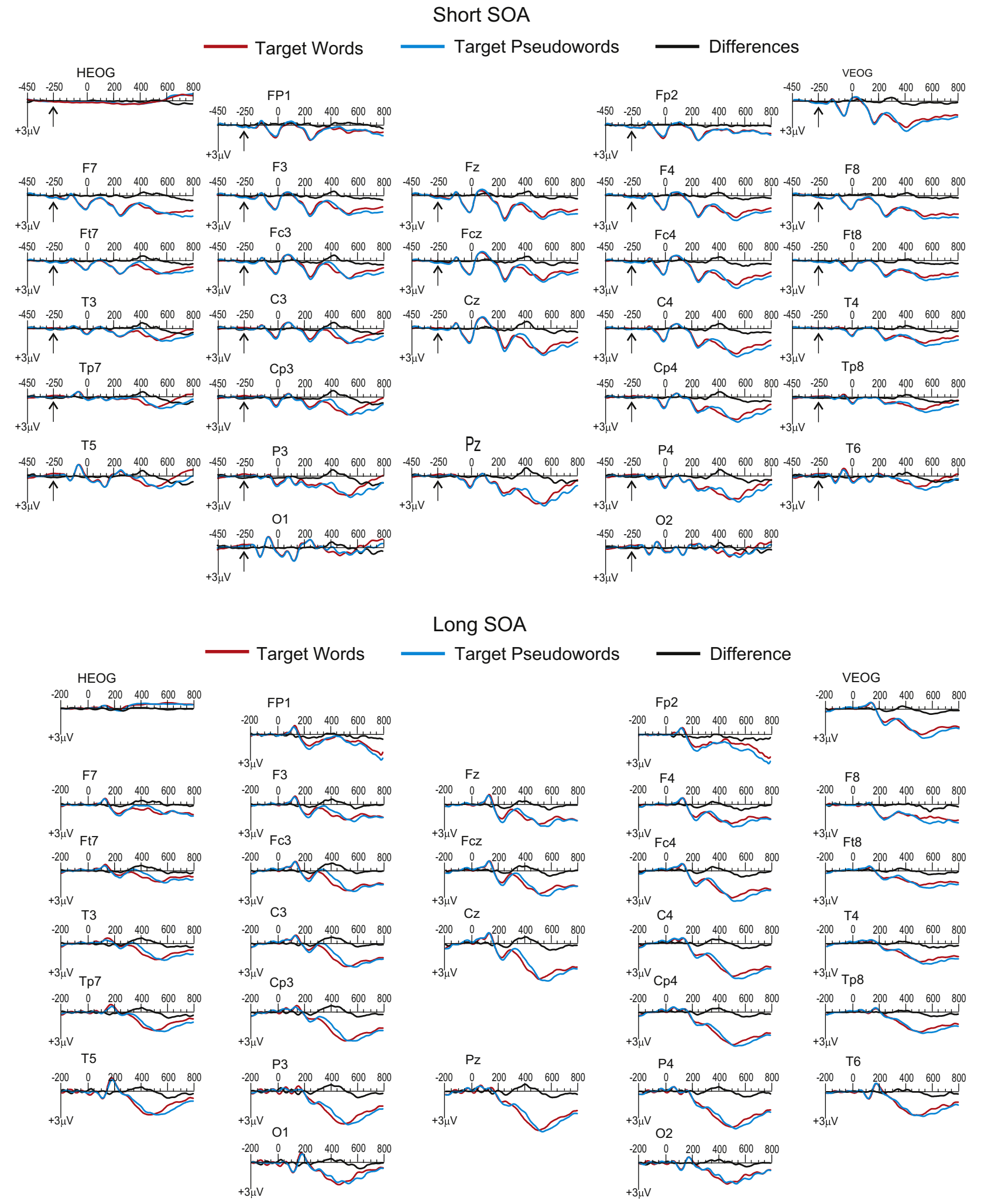

Fig. 3. Grand average ERPs $(N=22)$ to target words and pseudowords in the short (top) and the long SOA (bottom) in the lexical decision task. The difference wave (in black) was computed by subtracting words (in red) from pseudowords (in blue). For other details, see Fig. 2. (For interpretation of the references to color in this figure legend, the reader is referred to the web version of this article.)

(56 ms on average) than the short SOA (30 ms). However, the effect of priming was significant for both the short $\left(F_{1,18}=5.24, p=.035\right)$ and the long $\left(F_{1,18}=8.64, p=.009\right)$ SOAs.

\subsubsection{Electrophysiological data: mean voltage analyses}

Fig. 6 represents the grand averages ERPs elicited by the target words in the short (top) and the long SOA (bottom), separating 

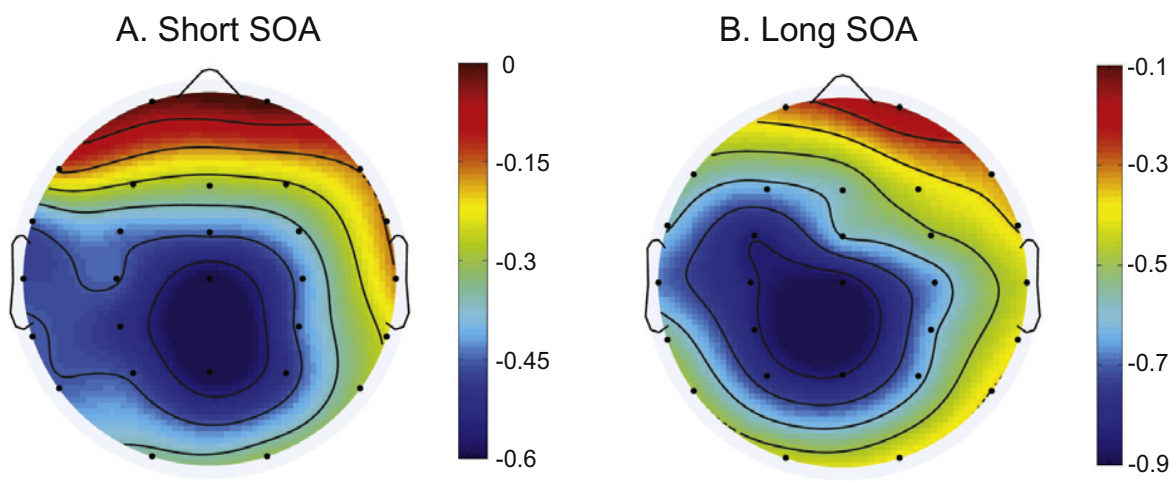

Fig. 4. Spline interpolated isovoltage maps of the effect of lexicality in the N400 time window in the lexical decision task. (A) Short SOA. (B) Long SOA.

A

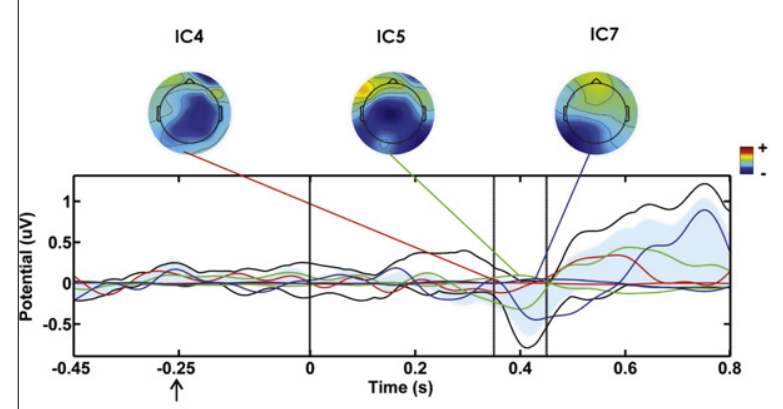

B

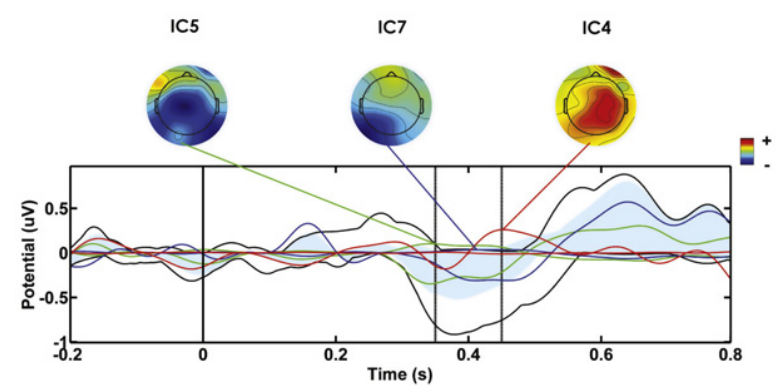

C

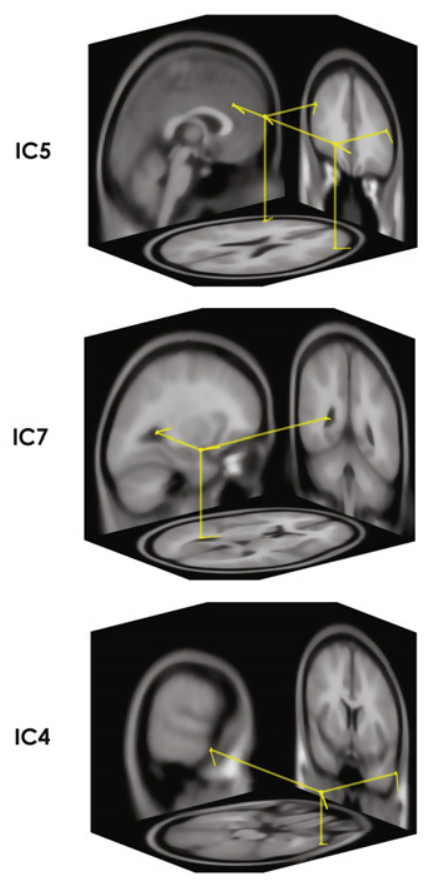

Fig. 5. Independent component contributions to the effects of lexicality in the N400 time window in the lexical decision task. (A) Short SOA. The vertical black line at time 0 indicates target word onset. The arrow in the timeline indicates prime onset. The thick black lines show the envelope, that is, the most positive and negative values of the ERPs over all channels and at each time point. The blue traces show the envelopes of the contribution of the independent components (ICs) represented. Each IC scalp map is connected to its data envelope by a color line that points to the moment of peak contribution to the ERP (see Delorme and Makeig, 2004). (B) Long SOA. (C) Equivalent current dipoles of the ICs that made the greatest contribution to the effect of lexicality in the N400 time window. The activity of these ICs did not significantly differ between SOAs. (For interpretation of the references to color in this figure legend, the reader is referred to the web version of this article.)

primed and unprimed trials. For unprimed trials at $\mathrm{Cz}$ electrode, the N400 deflections peaked around $320 \mathrm{~ms}$ after target onset in the short and around $290 \mathrm{~ms}$ in the long SOA. For both SOAs, N400 amplitudes were more negative for unprimed (in blue) than primed trials (in red).

Statistical analyses of the mean voltage amplitudes of the N400 revealed a main effect of semantic priming for each subset of electrodes $\left(F_{1,18}=14.51, p=.001\right.$ for the sagittal, $F_{1,18}=12.18, p=.004$ for the para-sagittal and $F_{1,18}=10.73, p=.004$ for the lateral subset of electrodes). At the sagittal subset, there was a trend for an interaction between priming and SOA $\left(F_{1,18}=3.61, p=.074\right)$. Follow-up analyses showed that the effect of priming was significant for both the short $\left(F_{1,18}=5.15, p=.036\right)$ and the long SOAs $\left(F_{1,18}=20.19\right.$, $p<.001)$. At the para-sagittal $\left(F_{1,18}=5.45, p=.036\right)$ and the lateral $\left(F_{1,18}=6.52, p=.02\right)$ subsets of electrodes, significant interactions between priming and SOA were found. Further analyses for these two subsets of electrodes showed that the effect of priming was significant for both SOA at the para-sagittal subset (long SOA: $F_{1,18}=18.78, p=.001$; short SOA: $F_{1,18}=4.21, p=.05$ ). For the lateral subset, the effect of priming was only significant in the long SOA $\left(F_{1,18}=26.43, p<.001\right)$. Despite this difference at the lateral subset, the effect of priming had a very similar distribution and a similar centro-parietal maximum in both SOAs, as illustrated by the voltage maps of Fig. 7.

\subsubsection{Electrophysiological data: independent component analysis (ICA)}

In the N400 time window, three independent components (IC2, IC4 and IC5) accounted for more than $80 \%$ of the effect of semantic priming in the short and the long SOAs (see Fig. 8A and B). 


\section{Short SOA}

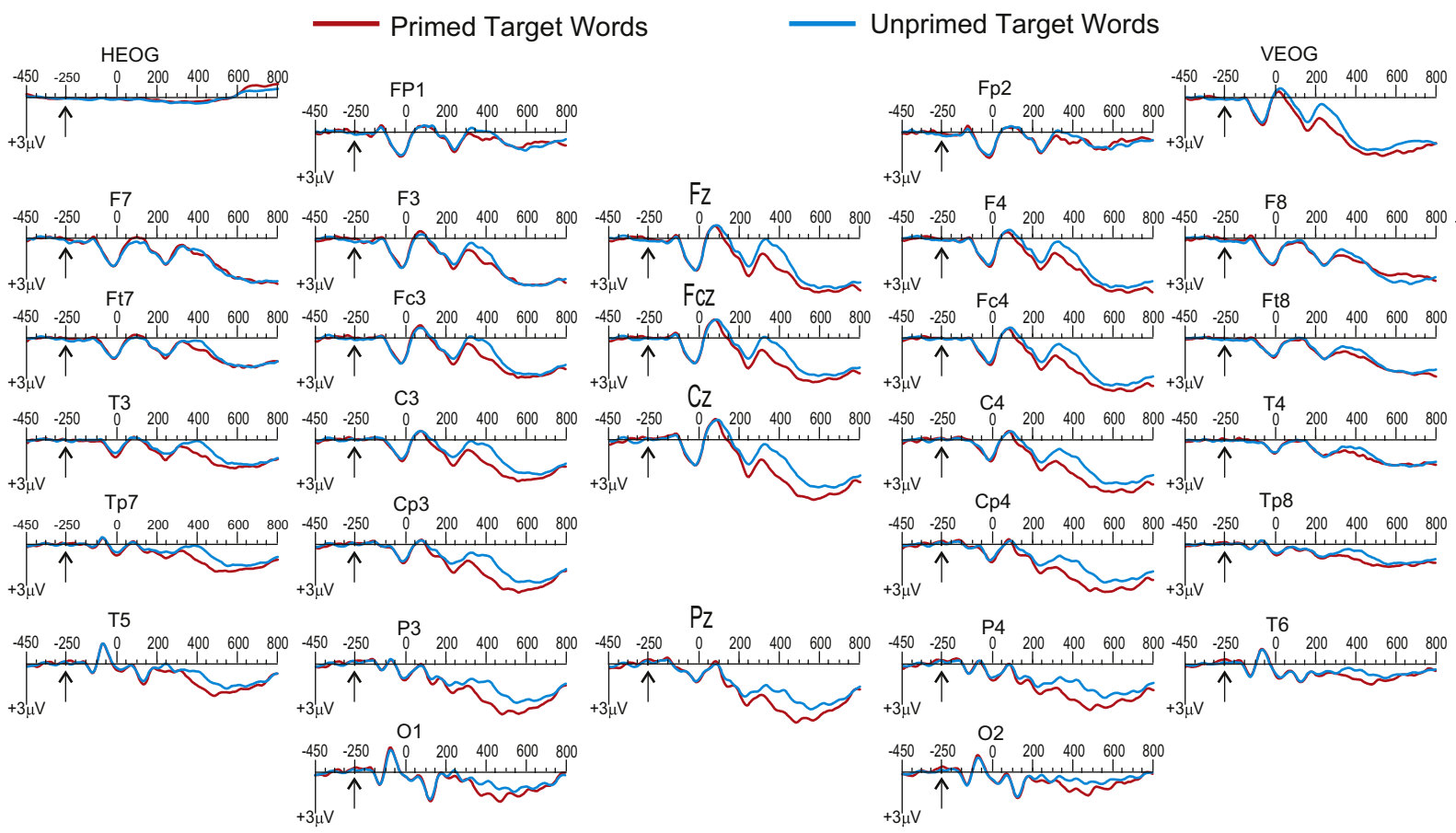

\section{Long SOA}

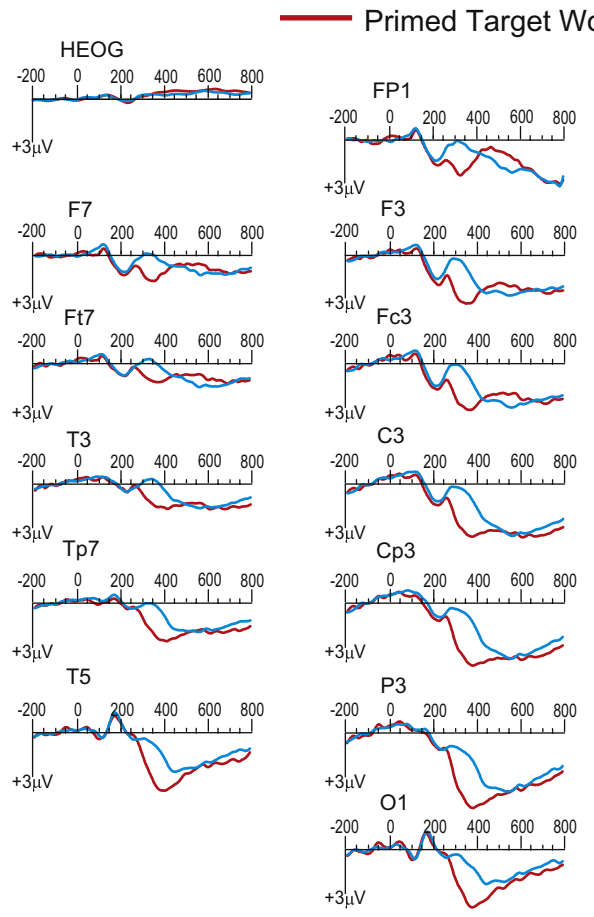

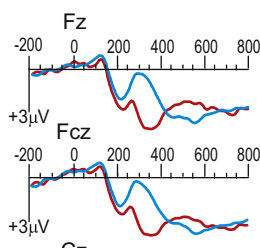

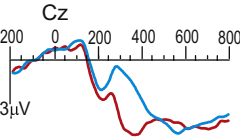

$\mathrm{Pz}$

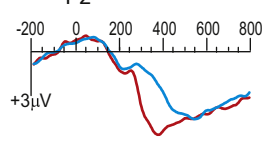

Unprimed Target Words
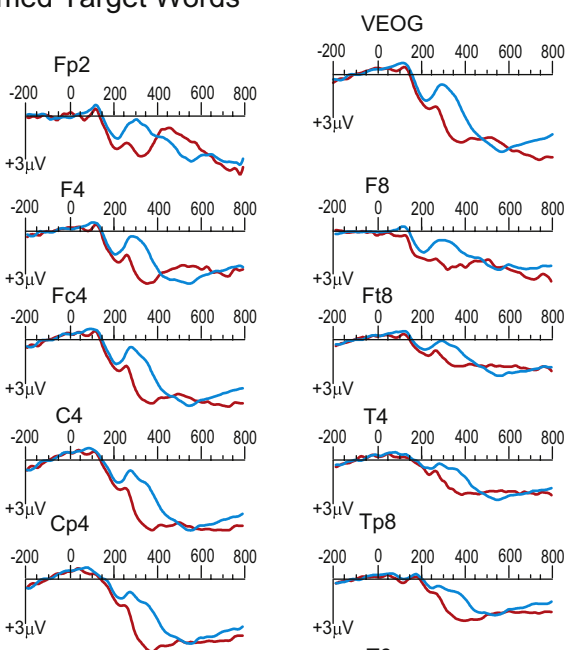

P4

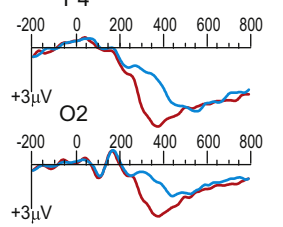

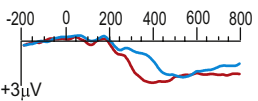

T6

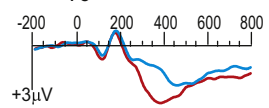

Fig. 6. Grand average ERPs $(N=19)$ to primed and unprimed target words in the short (top) and the long SOA (bottom) for the effect of semantic priming in the explicit semantic matching task. For other details see Fig. 2.

IC2 had a centro-parietal scalp distribution and was the greater contribution to the effect of semantic priming in the long $(\mathrm{PVAF}=55 \%)$ and the short $(\mathrm{PVAF}=35 \%)$ SOAs. This IC made its peak contribution to the effect of priming earlier in the long (382 ms after target word onset) than in the short SOA (460 ms after target onset). Statistical analyses of its mean activity showed a main effect of priming $\left(F_{1,18}=7.11, p=.016\right)$ but no significant interaction with SOA. Dipole source modeling for this IC revealed that it was best modeled with a bilateral source in the inferior parietal cortex (see Fig. 8C), in the vicinity of Brodmann area (BA) 40. $(x:-31, y:-42, z: 31)$. The residual variance of the dipole model (RVDM) was $5 \%$. 
A. Short SOA

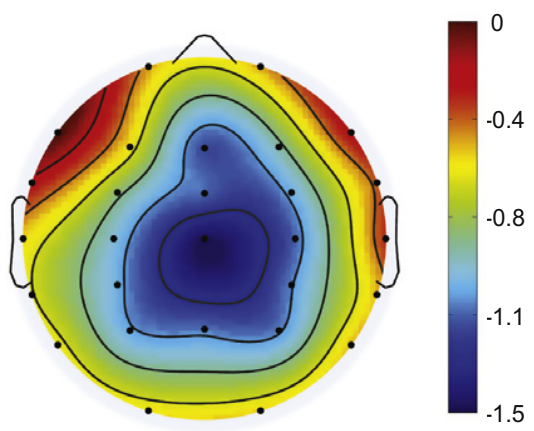

B. Long SOA

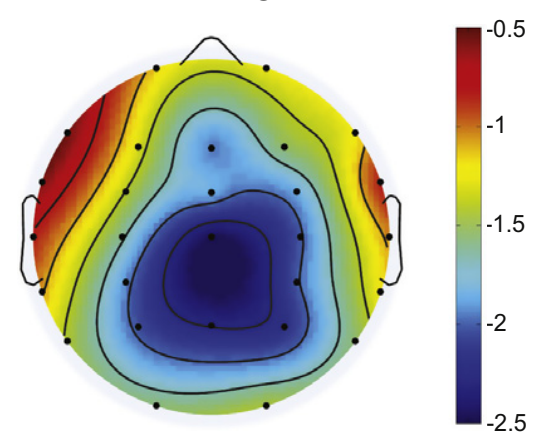

Fig. 7. Spline interpolated isovoltage maps of the effect of semantic priming in the N400 time window in the explicit semantic matching task. (A) Short SOA. (B) Long SOA.

A

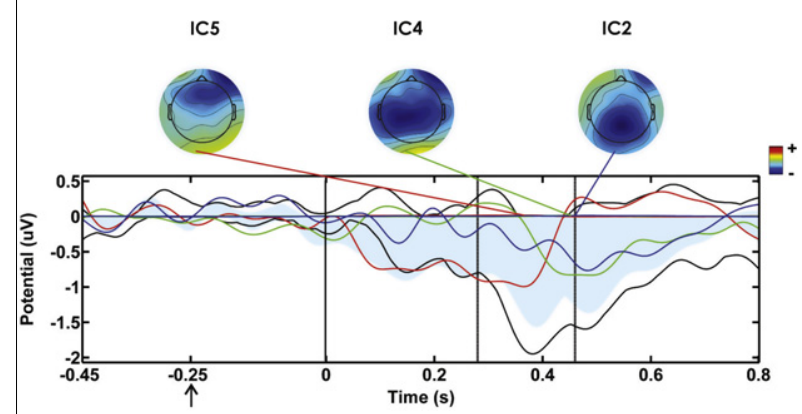

B

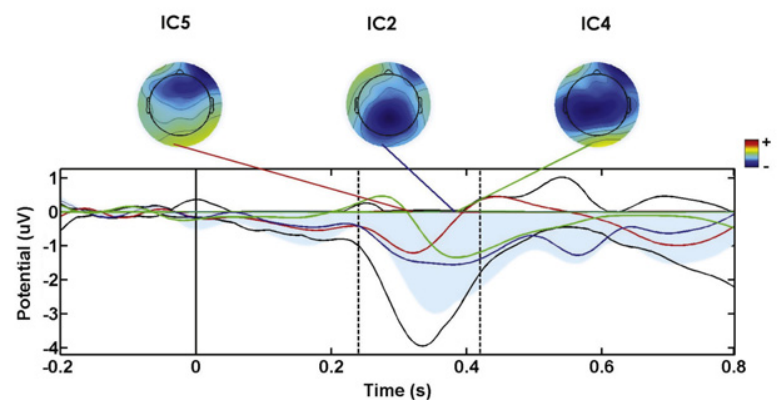

C

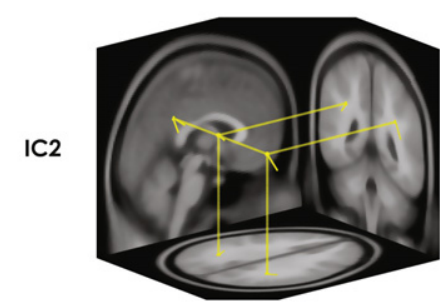

IC4

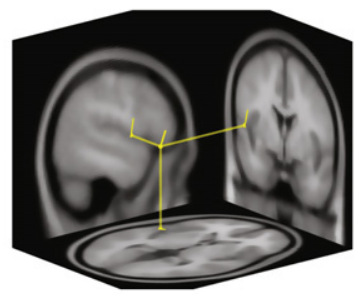

IC5

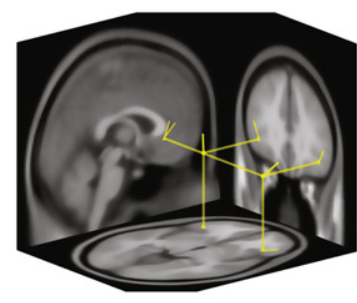

Fig. 8. Independent component contributions to the effects of semantic priming in the N400 time window in the explicit semantic matching task. (A) Short SOA. (B) Long SOA. (C) Equivalent current dipoles of the ICs that made the greatest contribution to the effect of semantic priming in the N400 time window. The activity of these ICs did not significantly differ between SOAs. For other details, see Fig. 5.

IC4 had a left centro-parietal scalp distribution and PVAFs of $34 \%$ and $27 \%$ in the short and long SOAs, respectively. As IC2, this IC made its peak contribution to the effect of priming later in the short (452 ms after target word onset) than in the long SOA (386 ms after target onset). Its mean activity significantly differentiated primed and unprimed words $\left(F_{1,18}=5.51, p=.031\right)$, but no interaction with SOA was found. This IC was best modeled as a generator in the left superior temporal gyrus, in the vicinity of BA22 ( $x$ : $-50, y: 0, z: 0)$, with a RVDM of $10 \%$.

IC5 had a frontal bilateral distribution and made a slightly greater contribution to the effect of semantic priming in the short $(\mathrm{PVAF}=35 \%)$ than in the long $(\mathrm{PVAF}=24 \%)$ SOA. This IC made its maximum contribution to the effect of priming earlier than the two others (i.e., $366 \mathrm{~ms}$ after target word onset in the short and $320 \mathrm{~ms}$ after target onset in the long SOA) and in the early part of the N400 window in both SOAs (see Fig. 8A and B). Statistical analyses of its mean activity showed that the effect of priming was just at significance level $\left(F_{1,21}=4.45, p=.05\right)$, but that there was no significant interaction with SOA. This IC was best modeled as a bilateral source in the inferior frontal gyrus in the vicinity of BA47 ( $x: 40, y: 29, z:-7$ ), with a RVDM of $6 \%$.

\section{Discussion}

The goal of the present study was to investigate in which experimental conditions semantic processing is preserved for repeated words. A number of studies have reported that semantic priming effects were reduced or suppressed in repeated conditions (Carroll and Kirsner, 1982; den Heyer and Benson, 1988; Besson et al., 
1992; Mitchell et al., 1993; Hanze and Meyer, 1995) and thus that repeated words may no longer be processed according to their semantic context. In contrast, we have recently shown preserved effects of semantic priming on RT and N400 despite the use of very high rates of repetition (Debruille and Renoult, 2009; Renoult and Debruille, 2011). To better understand these discrepancies, we manipulated parameters that are known to modulate semantic priming and investigated which of these would affect the semantic processing of repeated words. We contrasted a short $(250 \mathrm{~ms})$ and a long (1000 ms) SOA in two different experiments using a lower proportion of related words (30\%) than in our previous studies and associated word pairs instead of words sharing categorical relations. One group of participants performed a LDT and a second group performed an explicit semantic matching task with the same words (except for pseudowords). In both tasks, word stimuli consisted solely of two prime and two target words (plus two target pseudo words in the LDT) repeated throughout the experiment.

Results showed that the effects of semantic priming on RT and N400 were absent for both the short and the long SOA in the LDT. In this task, significant effects of lexicality, that is differences in processing between words and pseudowords, were nonetheless obtained for both SOAs. In the explicit semantic matching task, the effects of semantic priming on RT and N400 were significant for both SOAs and had similar scalp distribution and neural generators as in our previous studies. Compared to these studies, in which a greater proportion of related pairs were used, the magnitude of the effects of priming was only slightly smaller. Taken together, these results indicate that the task used, rather than SOA or the proportion of related words, is crucial for the maintenance of semantic processing with high rates of repetition. The fact that the present results were obtained with associated word pairs rather than words sharing categorical relations suggests that both types of relations could be studied with highly repeated words.

The use of an implicit or an explicit semantic task had major effects on the semantic processing of repeated words. In the LDT, no effects of semantic priming were found on RT and N400. These results are consistent with the reduction or suppression of semantic effects in repeated conditions found by previous studies using the LDT (James, 1975; Carroll and Kirsner, 1982; den Heyer and Benson, 1988; Kounios and Holcomb, 1994; Kiefer, 2005). In contrast, when using the same prime and target words in an explicit semantic matching task, the effects of priming on RT and N400 were significant. The present design did not include enough trials by condition to conduct a comparison of the effect of priming across repetition levels. However, such analysis was performed in our previous studies (Debruille and Renoult, 2009; Renoult and Debruille, 2011). It revealed in both cases that semantic priming did not interact with the level of repetition.

In the explicit semantic matching task, the main generators of the effect of semantic priming in the N400 time window were located in the left superior temporal gyrus and in the inferior parietal cortex bilaterally, as found in Renoult and Debruille (2011) and Renoult et al. (2010). Differences in laterality were however present compared with these studies. In Renoult and Debruille (2011), in which category and exemplar words were used instead of associate words, a bilateral source in the superior temporal gyrus and a right inferior parietal cortex generator were found as the main contributors of the N400 effect. It is unclear if these variations in laterality are due to differences in the processing of semantic and associative relations or to inherent limitations in the accuracy of the localization technique. The superior temporal gyrus (Helenius et al., 1998, 2002; Halgren et al., 2002; D’Arcy et al., 2004; Matsumoto et al., 2005) and the inferior parietal cortex (Nenov et al., 1991; Halgren et al., 1994; Guillem et al., 1995, 1999; Helenius et al., 1998) have also been found as generators of N400 in non-repeated conditions. In the present study, the activity of these N400 generators significantly differentiated primed and unprimed trials but the effect of priming did not interact with SOA.

The effects of SOA were relatively moderate in the present study. In the LDT, no effect of this variable was found. In the explicit task, the RT difference between primed and unprimed trials appeared to be greater in the long than the short SOA but the interaction between priming and SOA failed to reach significance. The N400 effect of semantic priming was found to be greater in the long than in the short SOA for the lateral subsets of electrodes. However, this effect was significant for both SOAs and had a very similar centro-parietal maximum. Moreover, as previously mentioned, the activity of the main generators of the effect was similar across SOAs. This similarity of the N400 effect of semantic priming across SOAs is thus comparable to that observed in studies using non-repeated designs (Boddy, 1986; Hill et al., 2002; Franklin et al., 2007) and confirms that the maintenance of this effect in repeated conditions does not depend on the use of long SOAs.

The proportion of related words used in both tasks was moderately low $(0.3)$. Thirty percent of related trials or less is usually categorized as a small proportion (e.g., Lucas, 2000), and so our relatedness proportion was at the high end of this estimation. However, in these conditions, we observed an absence of priming effects in the LDT, even in the long SOA. In contrast, in the explicit semantic matching task, the same relatedness proportion resulted in significant effects of semantic priming for both SOAs. These effects were of similar magnitude as those found in Debruille and Renoult (2009) and slightly smaller than those reported in Renoult and Debruille (2011), in which a greater relatedness proportion (0.5) was used. Even though it is likely that a smaller proportion than 0.3 would have resulted in smaller effect of semantic priming on RT and N400 in the explicit matching task (Brown et al., 2000; Holcomb, 1988; Chwilla et al., 1995), the present results suggest that the task used had much greater impact than the relatedness proportion on the maintenance of semantic processing with high rates of repetition.

In the LDT, significant effects of lexicality were found on RT and N400. As commonly found in N400 studies using non-repeated designs, this effect consisted of greater N400s for pseudowords than for words (Bentin, 1987; Holcomb and Neville, 1990; Holcomb, 1993; Chwilla et al., 1995). The main generators of this effect were found in the dorsolateral prefrontal cortex bilaterally, in the right middle temporal gyrus and the left hippocampus. Functional neuroimaging studies contrasting words and pseudowords presented visually have reported similar foci of activations, along with other sources in the angular gyrus and posterior cingulate cortex (Price et al., 1996; Hagoort et al., 1999; Tagamets et al., 2001; Binder et al., 2003). However, as noted by Mechelli et al. (2003), these studies have produced inconsistent results, in that few brain regions were consistently active across studies. The fact that the effect of lexicality, although relatively small, was still present in the present LDT may suggest that this effect has greater resistance to repetition than the effect of semantic priming. However, another possibility is that, as found for the latter effect, this maintenance of the effect of lexicality may be task-dependent. Accordingly, while semantic processing is implicit in the LDT, lexicality is an explicit effect in this task. Variations of this effect with task requirements have indeed been described in the literature. For instance, in Chwilla et al. (1995), lexicality effects on RT and N400 were greater in a LDT than in a letter case decision task. In a series of studies by Rugg and colleagues, in which pseudowords were repeated, greater repetition effects were found in a LDT than in a letter search task (Rugg and Nagy, 1987) or in a letter case decision task (Rugg et al., 1988). These studies suggest that the effects of lexicality can be increased by the use of a LDT. Unfortunately, as it is commonly the case, the explicit semantic matching task of the present 
study did not include pseudowords. It will thus be interesting in future studies to directly compare the effect of lexicality in implicit and explicit (i.e., LDT) conditions to further test if its resistance to repetition is task-dependent.

Very few studies have compared the N400 effects of lexicality and semantic priming. Chwilla et al. (1995) reported different scalp distributions for the two effects, with the former having a more frontal distribution than the latter. In the present study, both effects were maximal at centro-parietal sites, but the effect of lexicality was greater over the left hemisphere and the effect of priming greater over the right. In a recent study of McLaughlin et al. (2004), an effect of lexicality was found in adults beginning to learn a second language, while an effect of semantic priming only emerged when more hours of instruction had been accumulated (i.e., 14 and $63 \mathrm{~h}$ of instruction, respectively). These results along with our finding that N400 effects of lexicality and priming had different neural generators is compatible with the idea that these effects may have different functional significance, corresponding respectively to a lexical and a post-lexical effect. However, different group of participants performed the LDT and the explicit matching task and therefore different ICA decompositions were performed for the two groups. This allowed us to use the same stimulus material in both tasks but prevents a firm rejection of the hypothesis that similar neural correlates of the effects of priming and lexicality would have been found if the analyses had been done with the same subjects. Further studies will thus be necessary to confirm that these N400 effects have different neural generators.

Taken together, these results suggest that the choice of task is crucial for the maintenance of semantic processing with repeated presentations. While variations in SOA or in the proportion of related words are known to influence if semantic relations are processed automatically or more consciously, these variables seemed to have little effect on the preservation of the effects of semantic priming with repetition. In contrast, the task relevance of semantic relations (i.e., explicit versus implicit attention to semantics) had a major impact. Compared to implicit tasks like the LDT, the use of explicit semantic designs is not only associated with greater semantic effects on RT and N400 (Holcomb, 1988; Mitchell et al., 1991; West and Holcomb, 2000) and the activation of a greater number of sensory and motor features (Binder, 2007; Tomasino et al., 2008; Papeo et al., 2009) but also to a possible resistance to the sharpening of representations with repetition. Accordingly, the sharpening of semantic representations for repeated stimuli would only occur for features that are not essential to the task, as proposed by Wiggs and Martin (1998) for perceptual priming (see also Desimone, 1996). This is the case in LDTs and other implicit tasks in which access to the meaning of words and their specific semantic features is not necessary. As a result, some of these features may no longer be activated, thereby preventing other related concepts to benefit from this activation and resulting in an absence of semantic priming effects. In explicit semantic designs, the preservation of semantic processing for repeated presentations may allow the study of very specific conceptual categories with more homogeneous stimuli and more generally, the investigation of the organization of semantic representations at a finer scale than usual. As demonstrated in the present study and in Renoult and Debruille (2011), it should be possible to study the relations between individual concepts, whether they are associative like in the present study or categorical as in our previous study. These types of semantic paradigms will be useful in specific population, in which the use of numerous non-repeated targets is inherently problematic. For instance, in developmental studies, the use of repetition is sometimes necessary due to the small vocabulary size of participants. In studies involving schizophrenia patients, the use of such tasks may be useful to differentiate difficulty in processing contextual information from more general impairment in semantic memory (Debruille et al., 2010).

In conclusion, the maintenance of the effects of semantic priming with high rates of repetition does not seem to depend on the use of long SOAs or high proportions of related words. Indeed, these effects on N400 and RT were widely significant in an explicit semantic matching task both for a short and a long SOA and using a lower relatedness proportion than in our previous studies (Debruille and Renoult, 2009; Renoult and Debruille, 2011). In contrast, these effects were suppressed when using the same SOAs and relatedness proportion in a LDT with the same stimuli. Task instruction thus seems critical for the maintenance of semantic processing with repeated presentations, which suggests that explicit attention to semantics prevents semantic satiation.

\section{Acknowledgments}

This study was supported by Grant 194517-02 from the Natural Sciences and Engineering Research Council of Canada (NSERC) allocated to J.B. Debruille who is supported by the scholarship 10084 from the Fonds de la Recherche en Santé du Québec (FRSQ). Louis Renoult was supported by FRSQ fellowship 13542.

\section{References}

Bach P, Gunter TC, Knoblich G, Prinz W, Friederici AD. N400-like negativities in action perception reflect the activation of two components of an action representation. Soc Neurosci 2009;4:212-32.

Bell AJ, Sejnowski TJ. An information-maximization approach to blind separation and blind deconvolution. Neural Comput 1995;7:1129-59.

Bentin S. Event-related potentials, semantic processes, and expectancy factors in word recognition. Brain Lang 1987;31:308-27.

Bentin S, McCarthy G, Wood C. Event-related potentials, lexical decision, and semantic priming. Electroencephalogr Clin Neurophysiol 1985;60:353-5.

Besson M, Kutas M, Van Petten C. An event-related potential analysis of semantic congruity and repetition effects in sentences. J Cogn Neurosci 1992;4:132-49. Binder JR. Effects of word imageability on semantic access: neuroimaging studies. In: Hart J, editor. The neural basis of semantic memory. Cambridge, UK: Cambridge University Press; 2007.

Binder JR, McKiernan KA, Parsons ME, Westbury CF, Possing ET, Kaufman JN, et al. Neural correlates of lexical access during visual word recognition. J Cogn Neurosci 2003;15:372-93.

Binder JR, Desai RH, Graves WW, Conant LL. Where is the semantic system? A critical review and meta-analysis of 120 functional neuroimaging studies. Cereb Cortex 2009;19:2767-96.

Boddy J. Event-related potentials in chronometric analysis of primed word recognition with different stimulus onset asynchronies. Psychophysiology 1986;23:232-45

Brown CM, Hagoort P, Chwilla DJ. An event-related brain potential analysis of visual word priming effects. Brain Lang 2000;72:158-90.

Carroll M, Kirsner K. Context and repetition effects in lexical decision and recognition memory. J Verb Learn Verb Behav 1982;21:55-69.

Chang T. Semantic memory: facts and models. Psychol Bull 1986;99:199-220.

Chwilla DJ, Kolk HH. Accessing world knowledge: evidence from N400 and reaction time priming. Cogn Brain Res 2005;25:589-606.

Chwilla DJ, Brown CM, Hagoort P. The N400 as a function of the level of processing. Psychophysiology 1995;32:274-85.

Content A, Mousty P, Radeau M. Une base de données lexicales informatisée pour le français écrit et parlé. L'Année Psychologique 1990;90:551-66.

D'Arcy RC, Connolly JF, Service E, Hawco CS, Houlihan ME. Separating phonological and semantic processing in auditory sentence processing: a high-resolution event-related brain potential study. Hum Brain Mapp 2004;22:40-51.

Debruille JB, Renoult L. Effects of semantic matching and of semantic category on reaction time and $\mathrm{N} 400$ that resist numerous repetitions. Neuropsychologia 2009;47:506-17.

Debruille JB, Kumar N, Saheb D, Chintoh A, Gharghi D, Lionnet C, et al. Circumventing the deficit of context processing in schizophrenia: an eventrelated brain potential study. Int J Psychophysiol 2010;75:167-76.

Delorme A, Makeig S. EEGLAB: an open source toolbox for analysis of single-trial EEG dynamics including independent component analysis. J Neurosci Methods 2004;134:9-21.

den Heyer K, Benson K. Constraints on the additive relationship between semantic priming and word repetition and on the interactive relationship between semantic priming and stimulus clarity. Can J Psychol 1988;4:399-413.

den Heyer K, Goring A, Dannenbring GL. Semantic priming and word repetition: the two effects are additive. J Mem Lang 1985;24:699-716.

Desimone R. Neural mechanisms for visual memory and their role in attention. Proc Natl Acad Sci USA 1996;93:13494-9. 
Dien J, Khoe W, Mangun GR. Evaluation of PCA and ICA of simulated ERPs: Promax vs Infomax rotations. Hum Brain Mapp 2007;28:742-63.

Durgunoglu AY. Repetition, semantic priming, and stimulus quality: implications for the interactive-compensatory reading model. J Exp Psychol Learn Mem Cogn 1988; 14:590-603.

Electrode position nomenclature committee. American Electroencephalographic Society Guidelines for Standard Electrode Position Nomenclature. J Clin Neurophysiol 1991;8:200-2.

Elger CE, Grunwald T, Lehnertz K, Kutas M, Helmstaedter C, Brockhaus A, et al. Human temporal lobe potentials in verbal learning and memory processes. Neuropsychologia 1997;35:657-67.

Ferrand L, Alario FX. Normes d'associations verbales pour 366 noms d'objets concrets. L'Année Psychologique 1998;98:659-70.

Franklin MS, Dien J, Neely JH, Huber E, Waterson LD. Semantic priming modulates the N400, N300, and N400RP. Clin Neurophysiol 2007;118:1053-68.

Greenhouse GW, Geisser S. On methods of analysis of profile data. Psychometrika 1959;24:1582-9.

Groppe DM, Makeig S, Kutas M. Independent component analysis of event-related potentials. Cogn Sci Online 2008;6:1-44.

Guillem F, N'Kaoua B, Rougier A, Claverie B. Intracranial topography of event-related potentials N400/P600 elicited during a continuous recognition memory task. Psychophysiology 1995;32:382-92

Guillem F, Rougier A, Claverie B. Short- and long-delay intracranial ERP repetition effects dissociate memory systems in the human brain. J Cogn Neurosci 1999; 11:437-58.

Hagoort P, Brown C, Indefrey P, Herzog H, Steinmetz H, Seitz R. The neural circuitry involved in the reading of German words and pseudowords: a PET study. J Cogn Neurosci 1999;11:383-98.

Hagoort P, Hald L, Bastiaansen M, Peterson KM. Integration of word meaning and world knowledge in language comprehension. Science 2004:304:438-41.

Halgren E, Baudena P, Heit G, Clarke JM, Marinkovic K, Chauvel P, et al. Spatiotemporal stages in face and word processing 2: depth-recorded potentials in the human frontal and Rolandic cortices. J Physiol Paris 1994;88:51-80.

Halgren E, Dhond RP, Christensen N, Van Petten C, Marinkovic K, Lewine JD, et al. N400-like magnetoencephalography responses modulated by semantic context, word frequency, and lexical class in sentences. Neuroimage 2002;17:1101-16.

Hanze M, Meyer HA. Semantic priming and word repetition: the two effects are both additive and interactive. Psychol Res 1995;58:61-6.

Heinze HJ, Muente TF, Kutas M. Context effects in a category verification task as assessed by event-related brain potential ERP measures. Biol Psychol 1998; $47: 121-35$

Helenius P, Salmelin R, Service E, Connolly JF. Distinct time courses of word and context comprehension in the left temporal cortex. Brain 1998;121:1133-42.

Helenius P, Salmelin R, Service E, Connolly JF, Leinonen S, Lyytinen H. Cortica activation during spoken-word segmentation in nonreading-impaired and dyslexic adults. J Neurosci 2002;22:2936-44.

Hill H, Strube M, Roesch-Ely D, Weisbrod M. Automatic vs controlled processes in semantic priming-differentiation by event-related potentials. Int Psychophysiol 2002;44:197-218.

Hill H, Ott F, Weisbrod M. SOA-dependent N400 and P300 semantic priming effects using pseudoword primes and a delayed lexical decision. Int J Psychophysio 2005;56:209-21.

Holcomb PJ. Automatic and attentional processing: an event-related brain potential analysis of semantic priming. Brain Lang 1988;35:66-85.

Holcomb PJ. Semantic priming and stimulus degradation: Implications for the role of the N400 in language processing. Psychophysiology 1993;30:47-61

Holcomb PJ, Neville H. Auditory and visual semantic priming in lexical decision: a comparison using event-related brain potentials. Lang Cogn Proc 1990;4:281-312.

Hutchison K. Is semantic priming due to association strength or featural overlap? A "Micro-Analytic" review. Psychon Bull Rev 2003;10:785-813.

Hutchison KA, Neely JH, Johnson JD. With great expectations, can two "wrongs" prime a "right"? J Exp Psychol Learn Mem Cogn 2001;27:1451-63.

James C. The role of semantic information in lexical decisions. J Exp Psychol Hum Percept Perform 1975;104:130-6.

Jung TP, Makeig S, Westerfield M, Townsend J, Courchesne E, Sejnowski TJ. Analysis and visualization of single-trial event-related potentials. Hum Brain Mapp 2001;14:166-85.

Kiefer M. Repetition-priming modulates category-related effects on event-related potentials: further evidence for multiple cortical semantic systems. J Cogn Neurosci 2005;17:199-211.

Kounios J, Holcomb PJ. Concreteness effects in semantic processing: ERP evidence supporting dual-coding theory. J Exp Psychol Learn Mem Cogn $1994: 20: 804-23$.

Kutas M, Hillyard SA. Reading senseless sentences: brain potentials reflect semantic incongruity. Science 1980;207:203-5.

Kutas M, Hillyard SA. Brain potentials during reading reflect word expectancy and semantic association. Nature 1984;307:161-3.

Kutas M, Iragui V. The N400 in a semantic categorization task across 6 decades. Electroencephalogr Clin Neurophysiol 1998;108:456-71.

Kutas M, Van Petten C, Kluender R. Psycholinguistics electrified II: 1994-2005. In: Traxler M, Gernsbacher MA, editors. Handbook of psycholinguistics. 2nd ed. New York: Elsevier; 2006. p. 659-724.

Liu Y, Perfetti CA, Hart L. ERP evidence for the time course of graphic, phonological, and semantic information in Chinese meaning and pronunciation decisions. Exp Psychol Learn Mem Cogn 2003;29:1231-47.
Lucas M. Semantic priming without association: a meta-analytic review. Psychon Bull Rev 2000;7:618-30.

Lutkenhoner B. Dipole source localization by means of maximum likelihood estimation I. Theory and simulations. Electroencephalogr Clin Neurophysiol 1998;106:314-21.

Makeig S, Jung TP, Bell AJ, Ghahremani D, Sejnowski TJ. Blind separation of auditory event-related brain responses into independent components. Proc Natl Acad Sci USA 1997; $94: 10979-84$

Makeig S, Westerfield M, Jung TP, Covington J, Townsend J, Sejnowski TJ, et al. Functionally independent components of the late positive event-related potential during visual spatial attention. J Neurosci 1999;19:2665-80.

Martin A. Functional neuroimaging of semantic memory. In: Cabeza R, Kingstone A editors. Handbook of functional neuroimaging of cognition. Cambridge: MIT Press; 2001. p. 153-86.

Matsumoto A, lidaka T, Haneda K, Okada T, Sadato N. Linking semantic priming effect in functional MRI and event-related potentials. Neuroimage 2005;24:624-34.

McLaughlin J, Osterhout L, Kim A. Neural correlates of second-language word learning: minimal instruction produces rapid change. Nat Neurosc 2004;7:703-4.

Mechelli A, Gorno-Tempini ML, Price CJ. Neuroimaging studies of word and pseudoword reading: consistencies, inconsistencies, and limitations. J Cogn Neurosci 2003;15:260-71.

Mitchell PI, Andrews S, Fox AM, Catts SV, Ward PB, McConaghy N. Active and passive attention in schizophrenia: an ERP study of information processing in a linguistic task. Biol Psychol 1991;32:101-24.

Mitchell P, Andrews S, Ward PB. Event-related potential indices of semantic and repetition priming: effects of changing sentence context. Psychophysiology 1993;30:496-509.

Neely JH. Semantic priming effects in visual word recognition: a selective review of current findings and theories. In: Besner D, Humphreys GW editors. Basic processes in reading: visual word recognition. Hillsdale, NJ: Erlbaum; 1991. p. 264-336.

Nenov VI, Halgren E, Smith ME, Badier JM, Ropchan J, Blahd WH, et al. Localized brain metabolic response correlated with potentials evoked by words. Behav Brain Res 1991:44:101-4.

Onton J, Westerfield M, Townsend J, Makeig S. Imaging human EEG dynamics using independent component analysis. Neurosci Biobehav Rev 2006;30:808-22.

Papeo L, Vallesi A, Isaja A, Rumiati RI. Effects of TMS on different stages of motor and non-motor verb processing in the primary motor cortex. PLoS One 2009:4:e4508.

Pexman P, Hargreaves IS, Siakaluk PD, Bodner GE, Pope J. There are many ways to be rich: effects of three measures of semantic richness on word recognition. Psychon Bull Rev 2008;15:161-7.

Picton TW, Bentin S, Berg P, Donchin E, Hillyard SA, Johnson Jr R, et al. Guidelines for using human event-related potentials to study cognition: recording standards and publication criteria. Psychophysiology 2000;37:127-52.

Pitzer KD, Dagenbach D. A constraint on eliminating semantic priming by repeating a prime. Am J Psychol 2001;114:43-53.

Price CJ, Wise RJS, Frackowiak RSJ. Demonstrating the implicit processing of visually presented words and pseudowords. Cereb Cortex 1996;6:62-70.

Pulvermuller F. Words in the brain's language. Behav Brain Sci 1999;22:253-336.

Pulvermuller F, Shtyrov Y. Language outside the focus of attention: the mismatch negativity as a tool for studying higher cognitive processes. Prog Neurobiol 2006;79:49-71.

Renoult L, Debruille JB. N400-like potentials index semantic relations between highly repeated individual words. J Cogn Neurosci 2011;23:905-22.

Renoult L, Brodeur MB, Debruille JB. Semantic processing of highly repeated concepts presented in single-word trials: electrophysiological and behavioural correlates. Biol Psychol 2010;84:206-20.

Rugg MD, Nagy ME. Lexical contribution to non-word repetition effects: evidence from event-related potentials. Mem Cognit 1987;15:473-81.

Rugg MD, Furda J, Lorist M. The effects of task on the modulation of event-related potentials by word repetition. Psychophysiology 1988;25:55-63.

Scherg M. Fundamentals of dipole source potential analysis. In: Grandon F, Hoke M Romani GL, editors. Auditory evoked magnetic fields and potentials 1990; vol. 6. Karger: Basel; 1990. p. 40-69.

Smith ME, Stapleton JM, Halgren E. Human medial temporal lobe potentials evoked in memory and language tasks. Electroencephalogr Clin Neurophysiol 1986;63:145-59.

Tagamets MA, Novick JM, Chalmers ML, Friedman RB. A parametric approach to orthographic processing in the brain: an fMRI study. J Cogn Neurosci 2001;12:281-97.

Talairach J, Tournoux P. Co-planar stereotaxic atlas of the human brain. Thieme, Stuttgart; 1988

Tomasino B, Fink GR, Sparing R, Dafotakis M, Weiss PH. Action verbs and the primary motor cortex: a comparative TMS study of silent reading, frequency judgments, and motor imagery. Neuropsychologia 2008;46:1915-26.

West WC, Holcomb PJ. Imaginal, semantic, and surface-level processing of concrete and abstract words: an electrophysiological investigation. J Cogn Neurosci 2000;12:1024-37.

Wiggs CL, Martin A. Properties and mechanisms of perceptual priming. Curr Opin Neurobiol 1998;8:227-33.

Wilding J. Joint effects of semantic priming and repetition in a lexical decision task implication for a model of lexical access. Q J Exp Psychol 1986;38A:213-28. 